IZA DP No. 6910

Unequal Inequalities:

Do Progressive Taxes Reduce Income Inequality?

Denvil Duncan

Klara Sabirianova Peter

October 2012 


\title{
Unequal Inequalities: Do Progressive Taxes Reduce Income Inequality?
}

\author{
Denvil Duncan \\ Indiana University \\ and IZA \\ Klara Sabirianova Peter \\ University of North Carolina at Chapel Hill, \\ CEPR and IZA \\ Discussion Paper No. 6910 \\ October 2012
}

\author{
IZA \\ P.O. Box 7240 \\ 53072 Bonn \\ Germany \\ Phone: +49-228-3894-0 \\ Fax: +49-228-3894-180 \\ E-mail: iza@iza.org
}

Any opinions expressed here are those of the author(s) and not those of IZA. Research published in this series may include views on policy, but the institute itself takes no institutional policy positions. The IZA research network is committed to the IZA Guiding Principles of Research Integrity.

The Institute for the Study of Labor (IZA) in Bonn is a local and virtual international research center and a place of communication between science, politics and business. IZA is an independent nonprofit organization supported by Deutsche Post Foundation. The center is associated with the University of Bonn and offers a stimulating research environment through its international network, workshops and conferences, data service, project support, research visits and doctoral program. IZA engages in (i) original and internationally competitive research in all fields of labor economics, (ii) development of policy concepts, and (iii) dissemination of research results and concepts to the interested public.

IZA Discussion Papers often represent preliminary work and are circulated to encourage discussion. Citation of such a paper should account for its provisional character. A revised version may be available directly from the author. 
IZA Discussion Paper No. 6910

October 2012

\section{ABSTRACT \\ Unequal Inequalities: Do Progressive Taxes Reduce Income Inequality?}

This paper analyzes the effect of changes in structural progressivity of national income tax systems on observed and actual income inequality. Using several unique measures of progressivity over the 1981-2005 period for a large panel of countries, we find that progressivity reduces inequality in observed income, but has a significantly smaller impact on actual inequality, approximated by consumption-based GINIs. We show empirically that the differential effect on observed vs. actual inequality is much larger in countries with weaker legal institutions. Substantial differences in inequality response to changes in top vs. bottom rates are also uncovered. The paper discusses implications of these results for flat tax policies.

JEL Classification: $\quad \mathrm{H} 2, \mathrm{I3}, \mathrm{J} 3, \mathrm{O} 1, \mathrm{O} 2$

Keywords: income inequality, Gini, personal income tax, structural progressivity, tax evasion

Corresponding author:

Klara Sabirianova Peter

Department of Economics

Carolina Population Center

University of North Carolina - Chapel Hill

107 Gardner Hall, CB 3305

Chapel Hill, NC 27599

USA

E-mail:kpeter@unc.edu 


\section{Introduction}

That personal income tax structures contain a trade-off between efficiency and equity is considered conventional wisdom in the public finance literature (Ramsey, 1927; Mirrlees, 1971). It is commonly believed that efficiency is best achieved by the use of simple lump sum taxes that do not distort the choices that people make, whereas vertical equity generally requires graduated tax schedules accompanied by individual specific deductions, allowances, and credits, which are distortionary. As such, taxes that are efficient are thought to reduce equity and vice versa.

But are these two objectives always in conflict? Underlying this tradeoff is the presumption that a higher level of tax progressivity reduces income inequality. However, the presence of tax evasion undermines this commonly held view of progressivity. To the extent that tax rates and evasion are positively related, it is possible that both efficiency and equity could be reduced as a result of increased progressivity. This possibility arises if progressivity has a differential effect on observed inequality in reported income vs. actual inequality in true income in the presence of tax evasion.

In this paper, we seek to determine the relationship between structural progressivity of personal income taxes ${ }^{1}$ and income inequality, with a special emphasis on the differential effect of progressivity on observed vs. actual inequality. Although a lot of work has been done to assess the impact of tax reforms on equity, this is the first known attempt to differentiate between these two effects. Verification of this possible differential effect is becoming increasingly important given the number of countries that have or are considering the implementation of tax reforms with tax structures much flatter than their predecessors. Sabirianova Peter, Buttrick and Duncan (2010) shows that personal income tax (PIT) structures today have fewer tax brackets, lower top statutory marginal tax rates and reduced complexity than 25 years ago. They also identify what appears to be a shift towards flat rate income taxes. By 2012, at least 38 countries had adopted the flat rate PIT schedule and

\footnotetext{
${ }^{1}$ The term structural progressivity denotes changes in the average tax rate along the income distribution
} 


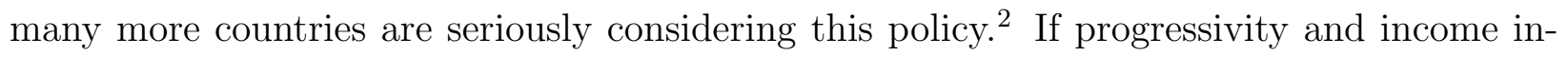
equality are negatively related, then there are important implications of such policies for the distribution of income. However, it is not clear that shifting to flat taxes or more generally, to income tax structures with lower levels of progressivity will necessarily lead to greater levels of income inequality in the presence of tax evasion.

Another important contribution of this paper is that we use a unique dataset for a large panel of countries that contains time-varying country-specific measures of structural progressivity of national personal income tax systems over the period 1981-2005. We develop and estimate several measures of structural progressivity for over one hundred countries worldwide by using complete national income tax schedules with statutory rates, thresholds, country-specific tax formulas and other information. The measures are based on data definitions that are compatible across countries as well as over time. This dataset allows our analysis to be different than most of the previous work, which has been country-specific incidence studies that rely on micro-simulation exercises or computable general equilibrium models (Gravelle, 1992; Martinez-Vazquez, 2008).

We do acknowledge that macro analysis has certain limitations as we are not able to examine within country heterogeneity in individual responses or directly estimate the tax evasion effect on income inequality. We also cannot account for the possible offsetting effects of other taxes. ${ }^{3}$ Nevertheless, macro data provide an exceptional opportunity for examining the relationship between structural progressivity and income inequality on a large international scale and for cross-country comparisons in testing several important hypotheses.

The key prediction of our decomposition framework is that progressivity affects ob-

\footnotetext{
${ }^{2}$ Iceland and Jamaica exited the "flat tax club" in 2010, but Jamaica restored its flat PIT in 2011. Some of the countries with the flat tax either have limited independence or are independent but disputed regions. Countries in the latter group are not recognized internationally.

${ }^{3}$ It is important to emphasize that we focus on the personal income tax only. As such, any equity offsets that may come from other taxes such as the corporate income tax or sales taxes are not taken into account. In principle, policy makers could achieve the same level of income inequality by substituting reduced progressivity of the personal income tax with increased progressivity of the corporate tax. We perform robustness checks of our results by controlling for available corporate income tax and sale tax rates for a smaller set of countries.
} 
served inequality differently than it does true inequality, and that the difference between the two inequality effects is increasing with the extent of tax evasion and its responsiveness to tax changes. To test this hypothesis, we use a country-level dataset of GINI coefficients calculated separately for gross income, net income, and consumption. We argue that the consumption-based measure of income is closer to true permanent income in comparison to disposable income reported in the household surveys. ${ }^{4}$ Our empirical analysis reveals that while progressivity reduces observed inequality in reported gross and net income, it has a significantly smaller impact on inequality in consumption. We show that the differential effect of progressivity on inequality in income vs. consumption is increasing with weaker legal institutions that can trigger a large tax evasion response. We find that weaker law and order are associated with significantly smaller negative (and sometimes even positive) effects of progressivity on inequality in consumption. We also find that progressivity changes at the top of the tax schedule are more effective in reducing income inequality than progressivity changes at the bottom. As expected, we find that progressivity has a larger negative effect on net income inequality than on gross income inequality.

The paper proceeds as follows. Section 2 provides the theoretical framework for decomposition of progressivity effects on inequality. Following that is a description of the data in section 3, the empirical model and results in section 4 and the conclusion in section 5 .

\section{The Relationship between Tax Progressivity and In- come Inequality}

Progressive taxes are often designed to collect a greater proportion of income from the rich relative to the poor, thus reducing the inequality of disposable income compared to taxable

\footnotetext{
${ }^{4}$ The empirical micro literature on developing countries has long pointed out the unreliability of income measures in household budget surveys due to widespread under-reporting and called for the use of consumption-based measures of inequality (e.g., see Deaton, 1997; Milanovic, 1999).
} 
income. However, as the government increases structural progressivity or tax rates facing the rich relative to the poor, individuals may respond by taking steps to reduce their taxable income. Reducing taxable income is achieved by either working less (productivity response) or simply reporting a smaller share of true income (tax evasion/avoidance response). While both behavioral responses are likely to reduce observed income inequality, they can have a differential effect on true income inequality. Although we expect the productivity response from more progressive taxes to reduce actual inequality, the evasion response may increase actual disposable income of the rich (since no taxes are paid on the hidden income) and thus increase inequality in actual net income.

The existing estimates of the productivity response based on the labor supply elasticity with respect to tax changes are rather modest (Eissa and Liebman, 1996; Blundell, Duncan and Meghir, 1998). However, they may well be understated as they do not account for other forms of productivity adjustment such as response in efforts, occupational mobility, job reallocation, investment, etc. Another common measure, the elasticity of taxable income, includes both the productivity and tax evasion responses (Chetty, 2009). Recently, Gorodnichenko, Martinez-Vazquez and Sabirianova Peter (2009)(GMP) propose to use consumption data to measure the productivity response to tax changes; they find a relatively small growth in consumption of wealthier households that faced smaller tax rates after the 2001 Russian flat rate income tax reform. At the same time, they estimate a significant increase in reported income (5 to 10 times larger than the consumption increase net of windfall gains), attributing the difference to improved tax compliance of households in the upper tax brackets. It has also been argued, in earlier studies, that the evasion/avoidance effect is much stronger in the upper tail of the income distribution (Slemrod, 1994; Feldstein, 1995). In other words, the rich tend to be more sensitive to changes in the tax rates because they are better able to hide their income. ${ }^{5}$

\footnotetext{
${ }^{5} \mathrm{~A}$ well documented result in the tax evasion literature is that compliance is highest among individuals whose income is easily verified by tax authorities. For example, wages can be more easily verified due to withholding. It is also generally accepted that wages as a share of total income decline as income increases. In other words, the rich has less verifiable income than the poor, and consequently they have more opportunities
} 
If the tax evasion response is indeed large, then the negative effect of higher and more progressive taxes on observed income inequality will significantly overstate (in absolute terms) their effect on the true distribution. Below we illustrate these possibilities more formally using the Kuznets ratio as a measure of inequality. We first decompose the effect of tax progressivity on observed income inequality and then on actual income inequality.

\subsection{Set-up for Decomposition of Progressivity Effects}

Consider an economy with two types of individuals: poor $(P)$ and rich $(R)$, where individuals are identical to everyone within their respective group. Let $Y_{i}^{0}, Y_{i}^{*}$, and $E_{i} \equiv Y_{i}^{*}-Y_{i}^{o}$ be gross observed, gross actual, and hidden income, respectively; $i$ takes values $p$ for poor and $r$ for rich.

Each group's level of reported income corresponds to two statutory tax brackets, with marginal tax rates $\tau_{p}$ for the low tax bracket and $\tau_{r}$ for the high tax bracket (See Panel A of Figure D). Also assume no deductions, credits, exemptions, or government transfers. ${ }^{6}$ The graduated personal income tax has a single threshold $B$ defined such that $Y_{p}^{o}<Y_{p}^{*}<B$ and $B<Y_{r}^{o}<Y_{r}^{*}$; that is, individuals earning less than the threshold are poor and those earning above the threshold are rich. This implicitly assumes that evasion activity among the rich does not lead to misclassification of individuals. In other words, the rich are correctly identified as rich even if reported income is the basis of the classification. ${ }^{7}$ With these assumptions, we can write down observed net income for the poor and rich as the difference between their observed gross income and corresponding tax liability:

$$
y^{o}= \begin{cases}Y_{p}^{o}-Y_{p}^{o} \tau_{p}=Y_{p}^{o}\left(1-\tau_{p}\right) & \text { if poor } \\ Y_{r}^{o}-\left[B \tau_{p}+\left(Y_{r}^{o}-B\right) \tau_{r}\right]=Y_{r}^{o}\left(1-\tau_{r}\right)+B\left(\tau_{r}-\tau_{p}\right) & \text { if rich }\end{cases}
$$

to hide their income.

${ }^{6}$ We introduce government transfers later in section 2.4.

${ }^{7}$ We allow for misclassification in Appendix A; i.e., we allow the rich to switch their income classification by reporting income below the threshold. The findings are consistent with the findings here, but depend on additional assumptions. 
Similarly, actual net income for the poor and rich can be derived as follows:

$$
y^{*}= \begin{cases}Y_{p}^{*}\left(1-\tau_{p}\right)+E_{p} \tau_{p} & \text { if poor } \\ Y_{r}^{*}\left(1-\tau_{r}\right)+B\left(\tau_{r}-\tau_{p}\right)+E_{r} \tau_{r} & \text { if rich }\end{cases}
$$

We use the Kuznets ratio, defined as average income of the rich divided by the average income of the poor, as our measure of inequality. Structural progressivity, on the other hand, can be defined as the ratio of the statutory marginal tax rates (marginal rate progression) or as the ratio of average tax rates (average rate progression). ${ }^{8}$ In either case, an increase (decrease) in $\tau_{r}\left(\tau_{p}\right)$ is consistent with an increase in progressivity. Therefore, it is possible to determine the effect of a change in progressivity on income inequality whether that change is due to a change in $\tau_{p}$ or $\tau_{r}$. This is illustrated in the next two sections for observed and actual income, respectively.

\subsection{Observed Inequality}

In this section we focus on observed net income inequality. Using equation (1), we write the Kuznets ratio for observed inequality as:

$$
I^{o}=\frac{Y_{r}^{o}\left(1-\tau_{r}\right)+B\left(\tau_{r}-\tau_{p}\right)}{Y_{p}^{o}\left(1-\tau_{p}\right)} .
$$

Differentiating with respect to $\tau_{r}$ yields:

$$
\frac{\partial I^{o}}{\partial \tau_{r}}=\frac{y_{p}^{o}\left[\left(1-\tau_{r}\right)\left(Y_{r}^{*^{\prime}}-E_{r}^{\prime}\right)-Y_{r}^{o}+B\right]}{\left[y_{p}^{o}\right]^{2}}
$$

which we decompose as:

$$
\frac{\partial I^{o}}{\partial \tau_{r}}=\frac{-\overbrace{\left(Y_{r}^{o}-B\right)}^{\text {Direct Effect }}+\overbrace{\left(1-\tau_{r}\right) Y_{r}^{*^{\prime}}}^{\text {Productivity Effect }}-\overbrace{\left(1-\tau_{r}\right) E_{r}^{\prime}}^{\text {Evasion Effect }}}{y_{p}^{o}}<0 .
$$

The first term in equation (4) shows the direct effect of $\tau_{r}$ on observed net income inequality in the absence of behavioral responses, and it is negative since we assume $Y_{r}^{o}>B$. The

\footnotetext{
${ }^{8}$ As demonstrated in Panel B of Figure D, the average tax rate increases with reported income, thus implying that the tax is progressive.
} 
negative direct effect arises simply from the fact that a progressive tax structure imposes a relatively higher tax burden on the rich. The next two terms in equation (4) include indirect behavioral responses, which we categorize as productivity and evasion effects, respectively. Changes in $\tau_{r}$ create a likely negative productivity response on the part of the rich, $Y_{r}^{*^{\prime}} \leq 0$. This assumption follows from the earlier discussion and is supported by numerous studies of labor supply elasticities. Since the marginal tax rate facing the poor does not change, we assume no behavioral response for the poor. Given recent empirical and theoretical results, hidden income of the rich most likely increases with $\tau_{r}$, i.e., $E_{r}^{\prime} \geq 0 .{ }^{9}$ Since the three terms in equation (4) move in the same direction, we can conclude - under mild assumptions - that an increase in progressivity via higher $\tau_{r}$ reduces observed income inequality.

Next, we consider the inequality effect of a change in progressivity via $\tau_{p}:{ }^{10}$

$$
\frac{\partial I^{o}}{\partial \tau_{p}}=\frac{-y_{p}^{o} B-\left(1-\tau_{p}\right) y_{r}^{o}\left(Y_{p}^{*^{\prime}}-E_{p}^{\prime}\right)+y_{r}^{o} Y_{p}^{o}}{\left[y_{p}^{o}\right]^{2}}
$$

which can be decomposed into three parts by combining the first and last terms:

$$
\frac{\partial I^{o}}{\partial \tau_{p}}=\frac{\overbrace{\left(1-\tau_{r}\right)\left(Y_{r}^{o}-B\right) Y_{p}^{o}}^{\text {Direct Effect }}-\overbrace{\left(1-\tau_{p}\right) y_{r}^{o} Y_{p}^{*^{\prime}}}^{\text {Productivity Effect }}+\overbrace{\left(1-\tau_{p}\right) y_{r}^{o} E_{p}^{\prime}}^{\text {Evasion Effect }}}{\left[y_{p}^{o}\right]^{2}}>0 .
$$

Equation (5) is composed of three terms. The first term is the combined direct effect of $\tau_{p}$ on the observed net income of the poor and rich, which is positive since $Y_{r}^{o}>B$. The remaining terms are the productivity and evasion effects on the poor. Because the productivity effect is negative and the evasion effect is positive, we can conclude that an increase in progressivity via lower $\tau_{p}$ also reduces observed inequality. ${ }^{11}$

\footnotetext{
${ }^{9} \mathrm{~A}$ majority of empirical studies find evidence of a positive relationship between tax rates and tax evasion (e.g., Clotfelter (1983); Slemrod (1985); Gorodnichenko, Martinez-Vazquez and Sabirianova Peter (2009). Feinstein (1991) is a notable exception. Fortin, Lacroix and Villeval (2007) find that the effect of tax rate on tax evasion is negative at low tax rates, but becomes positive as tax rates increase. Although the early expected utility theoretical models produce ambiguous results that depend on assumptions made about risk aversion and the structure of penalties (Allingham and Sandmo, 1972; Yitzhaki, 1974), more recently, Dhami and Al-Nowaihi (2007) argue that prospect theory might be a better alternative to expected utility models and derive an unambiguous positive relationship between tax rates and tax evasion.

${ }^{10}$ Since a change in $\tau_{p}$ does not affect the marginal tax rate of the rich, we do not expect the rich to respond on the intensive margin to a change in $\tau_{p}$; that is, $\frac{\partial Y_{r}^{*}}{\partial \tau_{p}}=\frac{\partial E_{r}}{\partial \tau_{p}}=0$.

${ }^{11}$ Note that an increase in $\tau_{p}$ implies a decrease in progressivity. Therefore, a positive relationship between
} 


\subsection{Actual Inequality}

We now turn our attention to actual inequality. Using equation (2), we define actual income inequality $I^{*}$ as the ratio of actual net income of the rich relative to that of the poor:

$$
I^{*}=\frac{Y_{r}^{*}\left(1-\tau_{r}\right)+B\left(\tau_{r}-\tau_{p}\right)+E_{r} \tau_{r}}{Y_{p}^{*}\left(1-\tau_{p}\right)+E_{p} \tau_{p}} .
$$

Holding the marginal tax rate of the poor $\tau_{p}$ constant, we can obtain the following partial effect of $\tau_{r}$ on actual income inequality:

$$
\frac{\partial I^{*}}{\partial \tau_{r}}=\frac{y_{p}^{*}\left[\left(1-\tau_{r}\right) Y_{r}^{*^{\prime}}-Y_{r}^{*}+B+\tau_{r} E_{r}^{\prime}+E_{r}\right]}{\left[y_{p}^{*}\right]^{2}}
$$

which may also be decomposed into three parts, since $Y_{r}^{o}=Y_{r}^{*}-E_{r}$ :

$$
\frac{\partial I^{*}}{\partial \tau_{r}}=\frac{-\overbrace{\left(Y_{r}^{o}-B\right)}^{\text {Direct Effect }}+\overbrace{\left(1-\tau_{r}\right) Y_{r}^{*^{\prime}}}^{\text {Productivity Effect }}+\overbrace{\tau_{r} E_{r}^{\prime}}^{\text {Evasion Effect }}}{y_{p}^{*}} \gtrless 0 .
$$

The direct effect and productivity response have the same qualitative negative impact on both observed and actual income inequality, as shown in equations (4) and (7). Unlike observed income inequality in equation (4), the evasion response, $E_{r}^{\prime}$, leads to an increase in actual income inequality in equation (7), making the sign of the derivative in equation (7) ambiguous. Comparing the relative size of the effect in $(7)$ with that of $(4)$ shows that $\frac{\partial I^{*}}{\partial \tau_{r}}$ is unambiguously larger than $\frac{\partial I^{\circ}}{\partial \tau_{r}}$. Therefore, we can conclude that an increase in progressivity via $\tau_{r}$ has a smaller negative effect on actual inequality than on observed inequality. In other words, as $\tau_{r}$ increases, the decrease in actual inequality is predicted to be smaller than the decrease in observed inequality. It is also clear that this differential effect increases with the responsiveness of evasion. ${ }^{12}$

$\tau_{p}$ and inequality is consistent with a negative relationship between progressivity and inequality.

${ }^{12}$ Theoretically, it is also possible for the derivative in equation (7) to switch sign (to positive) if $E_{r}^{\prime}$ is very large while $Y_{r}^{*^{\prime}}$ and $\left(Y_{r}^{o}-B\right)$ are small. 
Next we differentiate equation (6) with respect to $\tau_{p}$ to get:

$$
\frac{\partial I^{*}}{\partial \tau_{p}}=\frac{\left.-y_{p}^{*} B-y_{r}^{*}\left[\left(1-\tau_{p}\right) Y_{p}^{*^{\prime}}-Y_{p}^{*}+\tau_{p} E_{p}^{\prime}+E_{p}\right)\right]}{\left[y_{p}^{*}\right]^{2}}
$$

which we rewrite as equation (8), by combining $y_{r}^{*}\left(Y_{p}^{*}-E_{p}\right)$ and $y_{p}^{*} B$ :

$$
\frac{\partial I^{*}}{\partial \tau_{p}}=\frac{\overbrace{\left(1-\tau_{r}\right)\left(Y_{r}^{o}-B\right) Y_{p}^{o}+Y_{p}^{o} Y_{r}^{o}\left(\pi_{r}-\pi_{p} \sigma\right)}^{\text {Direct Effect }}-\overbrace{\left(1-\tau_{p}\right) y_{r}^{*} Y_{p}^{*^{\prime}}}^{\text {Productivity Effect }}-\overbrace{\tau_{p} y_{r}^{*} E_{p}^{\prime}}^{\text {Evasion Effect }}}{\left[y_{p}^{*}\right]^{2}} \gtrless 0,
$$

where $\pi_{r}=\frac{E_{r}}{Y_{r}^{o}}, \pi_{p}=\frac{E_{p}}{Y_{p}^{o}}$, and $\sigma=\frac{B}{Y_{r}^{o}}$. The first term in equation (8) is the combined direct effect on the poor and rich, which is positive under the highly plausible assumption that $\pi_{r}>\pi_{p} \cdot{ }^{13}$ The second term is also positive, since it includes the negative productivity effect. However, the third term capturing the positive evasion effect is negative, which makes the sign of equation (8) ambiguous. Unlike the case with $\tau_{r}$ in equation (7), we cannot determine with certainty whether $\tau_{p}$ has a larger or smaller effect on actual income inequality than on observed income inequality. What we can say with certainty, by comparing equations (8) and (5), is that the differential effect of $\tau_{p}$ on observed versus actual income inequality increases with larger evasion response. In other words, the larger is the evasion response, the smaller is the effect of progressivity via $\tau_{p}$ on actual inequality relative to observed inequality.

\subsection{Government Transfers}

In this section we allow for government transfers to the poor. We assume some exogenous share, $\delta$, of total tax revenues is shared equally among the poor. No particular assumption is made regarding the remaining portion of tax revenues; it could be used to cover tax administration costs and/or public goods. We define total tax revenues (TR) and total government transfer $(G)$ as:

\footnotetext{
${ }^{13}$ This assumption is sufficient but not necessary. Since $0<\sigma<1,\left(\pi_{r}-\pi_{p} \sigma\right)>0$ if $\frac{\pi_{r}}{\pi_{p}}>\sigma$. That is, the direct effect may be positive even if the poor's hidden income as a share of their observed income is greater than that of the rich.
} 


$$
\begin{aligned}
T R & =n_{p} Y_{p}^{o} \tau_{p}+n_{r}\left[Y_{r}^{o} \tau_{r}-B\left(\tau_{r}-\tau_{p}\right)\right], \\
G & =\delta * T R,
\end{aligned}
$$

where $n_{p}$ and $n_{r}$ are the number of poor and rich, respectively. We can write observed and actual income for the poor as:

$$
\begin{aligned}
& y_{p}^{o}=Y_{p}^{o}\left(1-\tau_{p}\right)+\frac{G}{n_{p}}, \\
& y_{p}^{*}=Y_{p}^{*}\left(1-\tau_{p}\right)+E_{p} \tau_{p}+\frac{G}{n_{p}},
\end{aligned}
$$

where $\frac{G}{n_{p}}$ is the amount of government transfers received by each poor individual, and this amount is non-taxable. The revised measure of observed income inequality thus becomes:

$$
I^{o}=\frac{Y_{r}^{o}\left(1-\tau_{r}\right)+B\left(\tau_{r}-\tau_{p}\right)}{Y_{p}^{o}\left(1-\tau_{p}\right)+\frac{G}{n_{p}}} .
$$

Again, our objective is to determine the effect of a change in progressivity on income inequality. This is achieved by differentiating equation (10) with respect to $\tau_{r}$ and $\tau_{p}$.

$$
\frac{\partial I^{o}}{\partial \tau_{r}}=\frac{-\overbrace{\left(Y_{r}^{o}-B\right)}^{\text {Direct Effect }}+\overbrace{\left(1-\tau_{r}\right) Y_{r}^{*^{\prime}}}^{\text {Productivity Effect }}-\overbrace{\left(1-\tau_{r}\right) E_{r}^{\prime}}^{\text {Evasion Effect }}}{\left[y_{p}^{o}\right]^{2}}-\frac{\overbrace{y_{r}^{o} G^{\prime}}^{\text {Redistributive Effect }}}{n_{p}\left[y_{p}^{o}\right]^{2}}<0
$$

where $G^{\prime}\left(=\frac{\partial G}{\partial \tau_{r}}=n_{r} \delta\left[\tau_{r} Y_{r}^{o^{\prime}}+\left(Y_{r}^{o}-B\right)\right]\right)$ is positive if the economy is on the upward sloping side of the Laffer curve; i.e., tax revenues and thus transfers to the poor increase with $\tau_{r}$. Equation (11) is similar to equation (4) except for the last term involving $G^{\prime}$ and the definition of $y_{p}^{o}$ (see equation (9)). As in equation (4), the sum of the first three terms is negative, which indicates that higher progressivity via an increase in $\tau_{r}$ leads to lower levels of inequality in observed net income. This negative effect is re-enforced by the introduction of pro-poor government transfers under the assumption that $G^{\prime}>0 .{ }^{14}$ This implies that the

\footnotetext{
${ }^{14}$ Of course, these conclusions do not hold if higher taxes reduce tax revenues. In this case, higher taxes lead to a reduction in tax revenues thus reducing transfers.
} 
effect of $\tau_{r}$ on observed inequality is more negative in the presence of government transfers; i.e., $\left.\frac{\partial I^{o}}{\partial \tau_{r}}\right|_{G>0}<\left.\frac{\partial I^{o}}{\partial \tau_{r}}\right|_{G=0}$.

We also show in Appendix B that:

$$
\begin{aligned}
& \left.\frac{\partial I^{o}}{\partial \tau_{p}}\right|_{G>0}<\left.\frac{\partial I^{o}}{\partial \tau_{p}}\right|_{G=0}, \\
& \left.\frac{\partial I^{*}}{\partial \tau_{r}}\right|_{G>0}<\left.\frac{\partial I^{*}}{\partial \tau_{r}}\right|_{G=0} \\
& \left.\frac{\partial I^{*}}{\partial \tau_{p}}\right|_{G>0}<\left.\frac{\partial I^{*}}{\partial \tau_{p}}\right|_{G=0} .
\end{aligned}
$$

In other words, pro-poor government transfers increase the redistributive effect of $\tau_{r}$ and $\tau_{p}$ on both observed and actual net income.

\subsection{Predictions}

The decomposition framework outlined above yields four very clear predictions. First, the effect of structural progressivity, whether through $\tau_{p}$ or $\tau_{r}$, on observed inequality is expected to be negative; $\left.\frac{\partial I^{o}}{\partial \tau_{r}}\right|_{G=0}<0$ and $\left.\frac{\partial I^{o}}{\partial \tau_{p}}\right|_{G=0}<0$. Second, the effect of $\tau_{r}$ on actual inequality is expected to be smaller compared to its effect on observed inequality; $\left.\frac{\partial I^{*}}{\partial \tau_{r}}\right|_{G=0}<\left.\frac{\partial I^{o}}{\partial \tau_{r}}\right|_{G=0}$. On the other hand, the effect of $\tau_{p}$ on actual inequality relative to observed inequality remains ambiguous. Third, the differential effect of structural progressivity on actual versus observed inequality increases with the level of evasion response. This holds whether progressivity is measured by a change in $\tau_{r}$ or $\tau_{p}$. The third prediction implies that the smaller effect on actual inequality is more likely to be found in environments where the evasion response is large. Finally, we show that structural progressivity has a larger negative effect on both

measures of income inequality when government transfers are pro-poor; $\left.\frac{\partial I^{\circ}}{\partial \tau_{i}}\right|_{G>0}<\left.\frac{\partial I^{o}}{\partial \tau_{i}}\right|_{G=0}$ and $\left.\frac{\partial I^{*}}{\partial \tau_{i}}\right|_{G>0}<\left.\frac{\partial I^{*}}{\partial \tau_{i}}\right|_{G=0}$ for $i \quad \epsilon \quad(r, p)$.

Our objective in the following sections is to test these hypotheses empirically. The major challenge for our empirical analysis is how to measure unobserved actual income. While we do not observe actual income in a typical household survey, expenditures or con- 
sumption are much closer to actual permanent income than is reported income. Individuals may feel more comfortable reporting their consumption levels because there is less association between consumption levels and personal income tax liability. Furthermore, consumption data are usually collected with the aid of consumption diaries, which increases the accuracy of reported consumption.

On the other hand, it is not uncommon for individuals to underreport their income in household surveys. For example, Gorodnichenko, Sabirianova-Peter and Stolyarov (2009) find that consumer expenditures in the Russian household survey match very closely per capita numbers from national accounts. At the same time, reported disposable income in the household survey is up to 30 percent lower than household income calculated in national accounts, thus generating a 30 percent gap between income and consumption expenditures in survey responses over a 10-year period. Similarly, Lemieux, Fortin and Frechette (1994) find evidence of a 37 percent gap between average reported income and consumption in a household survey for Quebec city, Canada, and Engstrom and Holmlund (2009) find that surveyed households with at least one self-employed member underreport income by approximately 30 percent on average in Sweden.

Income data also tend to suffer from recall bias, seasonality and other issues to a greater extent than consumption data (Deaton, 1997). Although consumption data also suffer from seasonality, the ability to smooth consumption over a few months makes consumption data a much better measure of actual income. According to Deaton (1997), these problems, which favor the use of consumption data, are more serious in developing countries where a large proportion of the population tends to be self-employed primarily in agriculture.

Using consumption as our measure of actual income, we formulate four hypotheses that can be tested with macro data.

Hypothesis 1: An increase in structural progressivity leads to lower income inequality as measured by observed reported net income.

It is clear from equation (12) that redistribution in the form of transfers and other 
social welfare programs plays an important role in determining the redistributive properties of the income tax system. The higher the level of redistribution, $G$, the more effective will be the income tax system in equalizing income levels. This implies that countries with institutional structures that facilitate redistribution through transfers, such as democratic political systems, should be more effective in reducing inequality via its personal income tax. In other words, any factor that increases government transfers to the poor should reinforce the effect of progressivity on observed income inequality. This effect is captured by the following hypothesis:

Hypothesis 2: Factors that are positively associated with pro-poor redistribution such as democracy and civil liberties are likely to reinforce the negative effect of structural tax progressivity on observed income inequality.

The third hypothesis follows from our prediction that an increase in structural progressivity should lead to a more sizeable reduction in observed income inequality than in actual income inequality. Assuming consumption is a better proxy for actual income allows us to test the following hypothesis:

Hypothesis 3: The effect of structural progressivity on inequality in actual income is likely to be smaller than the effect of structural progressivity on inequality in observed net income. This hypothesis is most likely to hold when progressivity changes occur at the top of the income distribution.

Another implication of the model is that the difference between the effect of tax changes on actual inequality and their effect on observed inequality is expected to increase with the response of tax evasion. Since the evasion response is not observable in our data, we cannot test this hypothesis directly. However, we can see whether observable factors that increase the responsiveness of tax evasion attenuate the effect of structural progressivity on actual inequality (or make the effect less negative). The weakness of legal institutions could be one of such factor as it is likely to be positively correlated with the evasion elasticity. For example, Slemrod and Kopczuk (2002); Kopczuk (2005) make the point that the elas- 
ticity of taxable income (ETI) is a function of the characteristics of the tax system (also see Saez, Slemrod and Giertz, 2012, for an extenisive review). In particular, the ETI is larger in environments with many evasion/avoidance opportunities. To the extent we can measure the strength of legal institutions, we may anticipate that a positive effect of structural progressivity on actual inequality is more likely to be found in countries with weaker legal institutions. This leads to our final hypothesis:

Hypothesis 4: The differential effect of structural progressivity on consumption versus reported income inequality is likely to be larger in countries with weaker legal institutions. A positive effect on consumption inequality is also possible in those countries.

\section{Measuring Inequality and Structural Progressivity}

\subsection{Income Inequality Measure}

We test the hypotheses developed in the previous section using country-level GINI coefficients obtained from the World Institute for Development Research (WIDER v.2c), the World Development Index (WDI), the International Labor Office (LABORSTA), the European Commission (EUROSTAT), and the Review of Economic Dynamics (RED) ${ }^{15}$ The WIDER GINI estimates are widely used to study cross country income inequality primarily because of the relatively large country year coverage. The GINI coefficients are based on income and consumption data collected in household surveys by the respective countries. Because surveys vary across countries and time, numerous steps are taken to ensure accuracy and consistency. In particular, careful attention is paid to the types of incomes covered, the use of equivalence scales, and the representativeness of the underlying surveys. Furthermore, each GINI is assigned a quality rating based upon area and population coverage, income concepts, survey design, sampling methods, missing information and overall data quality.

\footnotetext{
15 The RED data are taken from papers published in the special issue on Cross Sectional Facts for Macroeconomists; Volume 13, Issue 1 (January 2010). It includes data from Canada, Germany, Italy, Mexico, Russia, Spain, Sweden, United Kingdom, and the US. See Table 8 for more details.
} 
Similarly, the RED data have consistent measures of income and consumption inequality across years and countries. Data from the remaining sources are used to the extent that we are able to observe the level of details provided in the RED and WIDER samples.

For the purpose of our analysis, we select all GINI coefficients that are based on one of the three income definitions: gross income, disposable (net) income, and expenditures or consumption. ${ }^{16}$ Gross income covers wages and salaries, self-employed income, and property income and is before taxes and transfers. Disposable income is defined similarly, but after taxes and transfers. GINIs are classified as expenditure-based if durables are included at purchase-value and as consumption-based if durables are either excluded or included at usevalue. The selected GINIs are grouped into 3 categories of area coverage (national, urban or national with exclusions, and other), 4 categories of income adjustment (equivalence scale, per capita adjustment, no adjustment, and unknown), and 4 categories of data quality rating. ${ }^{17}$ We average multiple GINI measures by country, year, income base, area coverage, income adjustment, and quality rating. Then, for a given country, year, and income base, we select one average measure using the following set of preferences: national estimates are preferred to urban, rural and other area coverage estimates, equivalence scales or per capita adjustment are chosen over no or unknown adjustment, higher quality ranking is preferred to lower quality ranking.

This selection process leaves us with 2112 GINI estimates for 151 countries from 1981 to 2005 in our estimation sample. ${ }^{18}$ The majority of the estimates meet the best practices as set out by the WIDER. Table 7 shows that $75 \%$ have been adjusted for the household size, $94 \%$ of the GINI estimates have national coverage, and $73 \%$ have a good quality rating, 1 or 2 . Of the total sample of GINI estimates, $27 \%$ are based on consumption, $32 \%$ on

\footnotetext{
${ }^{16}$ The initial number of observations by data source is: EUROSTAT (154); LABORSTA (221); WDI (544); WIDER (3424); and RED (383).

${ }^{17}$ The data quality rating is designed by the WIDER. It ranges from 1 to 4 , where 1 denotes observations with sufficient information on the quality of the income concept and the survey. For the other data sources, we assign 1 to Eurostat and RED, 2 to ILO, and 2.5 to WDI estimates.

${ }^{18}$ The sample includes only countries that were independent in a corresponding year. To avoid double counting, we exclude GINIs for the parts of the former unified countries like USSR or Yugoslavia prior to their breakup.
} 
gross income, and $40 \%$ on net income. To control for differences in GINI measurement, our estimates include dummy variables for income base, area coverage, and income adjustment categories. While we recognize that the use of dummy variables does not eliminate all of the biases resulting from comparability issues (Atkinson and Brandolini, 2001), we are constrained by existing inequality estimates. This is especially restricting in cross-country panel studies due to variations in the quality of primary data sources, differences in definition of variables and other procedures followed by individual countries.

In an effort to identify the trend in income inequality over time, we regress the GINI coefficients on a quadratic time trend, controlling for income base, area coverage, income adjustment, and country classification. ${ }^{19}$ The coefficients on the time terms are then used to plot the average GINI trend in Figure. The results indicate that income inequality increased throughout the 80s and 90s before declining during the 2000-2005 period. Figure also reports the time trend weighted by a country's GDP in constant U.S. dollars and population. ${ }^{20}$ While the GDP-weighted trend follows that of the unweighted, the population-weighted trend shows income inequality increasing throughout the sample period, which is consistent with rising inequality in China, India, and other developing countries with large populations.

Panel A of Table 1 provides additional summary statistics on the GINI coefficient by income definition across time. These numbers require careful interpretation because of comparability issues. In particular, the income-based and expenditure-based measures cannot be compared without a regression framework because the latter oversamples low and lower middle income countries while the former oversamples high and upper middle income countries (see Figure ). Bearing in mind this important caveat, the table shows that the consumption-based GINI follows the unweighted trend in Figure; increasing from a low of

\footnotetext{
${ }^{19} \mathrm{~A}$ similar, though not identical, procedure is used by Easterly (2007) to address the consistency problem inherent in the GINI data. Country categories are defined using the World Bank country classification based on historical (time-varying) income thresholds. For example, the income thresholds used for the 2005 classification are as follows: low income, $\$ 875$ or less, lower middle income, $\$ 876$ - $\$ 3465$, upper middle income, $\$ 3466-\$ 10725$, and high income, $\$ 10725$ or more.

${ }^{20}$ We suspect that population may be the better of the two weights since inequality is essentially an individual concept.
} 
32 in the early 1980s to a high of 38 in the early 1990s before declining to a low of 37 in the last period of the sample. From Figure, we can conclude that this pattern of change is driven primarily by low and lower middle income countries. Based on the income measures, we observe that gross (net) income inequality increased from 39(30) in the early 1980s to 42(36) in mid 1990s before falling back to 39(31) in the last period. We also observe that gross income is most unequally distributed followed by consumption and net income. These patterns are consistent with the literature (e.g., Easterly, 2007).

\subsection{Tax Progressivity Measures}

In contrast to income inequality, the measures of tax progressivity are not readily available for cross-country comparison. The existing measures implemented in the literature fall into one of three groups: 1) the top statutory PIT rate, 2) effective inequality-based measures of progressivity, and 3) structural progressivity measures. In their original form, none of these measures are perfectly suitable for our analysis.

The top statutory PIT rate is a legally determined marginal tax rate applicable to the top bracket of the income tax schedule. Although this tax rate has occasionally been used in empirical cross-country research as a proxy variable for tax progressivity, it might be a misleading indicator of progressivity since both proportional and highly progressive tax systems may, in principle, have the same top statutory rate. In fact, the correlation between the top rate and other progressivity measures introduced below is rather low. The correlation ranges from 0.25 to 0.45 . Nonetheless, we do not discard this variable and will employ it in some specifications for comparative purposes. $^{21}$

The effective progressivity is based on a predetermined indicator of income inequality. In its simplest form, effective progressivity is the ratio of after-tax GINI to before-tax GINI

\footnotetext{
${ }^{21}$ As an alternative to the top statutory PIT rate, some studies employ the income-weighted average marginal tax rate (Easterly and Rebelo, 1993). While this approach can capture the average marginal rate, it does not measure the PIT progressivity. This approach also imposes strong distributional assumptions on the marginal tax schedule which we are able to avoid due to the information that we have on each country's personal income tax schedule.
} 
and measures the extent to which a given tax structure results in a shift in the distribution of income toward equality (Musgrave and Thin, 1948). More sophisticated measures have been proposed by Kakwani (1977), Suits (1977), and others. The inequality-based measures generally require information on pre and post-tax inequality and the distribution of the tax burden. Information on these variables is either not available or not comparable across countries. The more serious problem, though, is the issue of simultaneity in determination of income inequality and inequality-based progressivity, which inhibits the identification of the direct effect of tax progressivity on inequality.

From this perspective, the measures of structural progressivity are more suitable for the purpose of our analysis. The term structural progressivity denote changes in average and marginal rates along the income distribution (Musgrave and Thin, 1948). These changes can be identified without knowing after-tax inequality, making the endogeneity problem less severe. However, the calculations require information on gross income distribution, which is difficult to gather in a comparable way at the cross-country level. Because structural progressivity changes along the income distribution, it produces a range of possible measures instead of one. However, we need a single, comprehensive measure of PIT progressivity, which is comparable across countries, available for a large representative sample of countries, and vary over time. We propose the following procedure to derive such a measure.

The first step in calculating structural progressivity is to obtain tax rates at different points of the income distribution. Instead of actual income distribution, we use a country`s per capita GDP and its multiples as a comparable income base. The GDP figures are rescaled to get 100 units of pre-tax income for each country and year, ranging from 4 percent to 400 percent of a country's per capita GDP. We then apply the tax schedule information to these units of income to obtain tax liability and average and marginal tax rates. The data on national tax schedules is collected for 189 countries from 1981 to 2005 and described in detail in Sabirianova Peter, Buttrick and Duncan (2010). Here we only note that our average and marginal tax rates take into account standard deductions, basic personal allowances, tax 
credits, major national surtaxes, multiple schedules, non-standard tax formulas, and other provisions in addition to statutory rates and thresholds. ${ }^{22}$

The progressivity measures are obtained by regressing average tax rates on gross income using 100 data points that are formed relative to a country's per capita GDP in a given year. The slope coefficient on the income variable measures the percentage point change in the tax rate resulting from a one percentage point change in gross income and is our measure of structural progressivity. The PIT structure is interpreted as progressive, proportional, or regressive if the slope coefficient is positive, zero, or negative, respectively. This procedure gives us average rate progression (ARP) for each country and year in our dataset. In a similar vein, we use marginal rates to compute marginal rate progression (MRP). However, since the concept of tax progressivity generally applies to average taxes, we focus on ARP and use MRP for comparative purposes only. Figure 2 illustrates how the ARP is obtained for a hypothetical case with no allowances or other provisions.

It should be noted that structural progressivity can deviate significantly from the nominal progressivity of the legal tax scale. This is especially pertinent to low income countries, where taxable income of the majority of population is often below the first tax threshold. Based on our procedure, countries for which a significant proportion of the population does not pay taxes will have progressivity measures of zero or close to zero. This makes sense, since the tax structure is effectively proportional when no one is paying taxes, even if the statutory rate schedule is highly graduated.

We impose a linearity restriction on the relationship between rates and income levels to obtain a single, comprehensive measure of progressivity. Given that the nominal tax schedule has a top statutory marginal rate, both the average and marginal rate progression measures, as defined by Musgrave and Thin (1948), decline as one moves up the income distribution. In other words, the tax schedule is less progressive at the top of the income scale. In an effort to capture this nonlinearity, we also calculate ARP for the bottom, middle,

\footnotetext{
${ }^{22}$ We do not account for deductions, allowances, and credits that vary by individual characteristics; for example, child credits are not included in our calculations.
} 
and top portion of the income scale, respectively. ${ }^{23}$

Panel B of Table 1 reports summary statistics on the six progressivity measures across time for the estimation sample. To infer the global trend, mean values are weighted by a country's share in world GDP and world population. The pattern that stands out is that all of the measures declined throughout the 1980s and early 1990s and then remained stable during the latter period, with the exception of ARP2 that declined steadily over the whole period. In concordance with the non-linear properties of progressivity (Musgrave and Thin, 1948), our measures calculated for the bottom portion of the income scale tend to be larger than those for the full income scale. Table 2 also reports summary statistics on the top statutory PIT rate. The top marginal tax rate has declined steadily from a high of 51 percent in the 1981-1985 period to a low of 32 percent in the 2001-2005 period. Since these global trends follow closely those reported in Sabirianova Peter, Buttrick and Duncan (2010), we refer the reader to that paper for a more detailed description of the changes that have taken place over the last 25 years.

\section{Empirical Methodology}

The decompositional framework discussed above yields four hypotheses, which we test in this section by modeling inequality as:

$$
I_{i t m}=\beta_{0 m}+\delta_{m} P_{i t}+\beta_{1 m} Z_{i t}+\beta_{2 m} W_{i t m}+\zeta_{t m}+\epsilon_{i t m} \quad \forall m \in(n, c),
$$

where $I_{i t m}$ is the GINI coefficient for income base $m$ ( $=n$ for income and $c$ for consumption) in country $i$ and year $t, P_{i t}$ is the relevant measure of PIT progressivity, $Z_{i t}$ is a vector of control variables (discussed below), $W_{i t m}$ is a vector of auxiliary variables, $\zeta_{t m}$ captures time effects, and $\epsilon_{i t m}$ is the error term. Vector $W$ controls for consistency of the GINI measures and includes a dummy for national area coverage, quality of GINI measure, and equivalent scale adjustment.

\footnotetext{
${ }^{23}$ This corresponds to 4-200, 100-300, and 200-400 percent of per capita GDP, respectively.
} 
The key parameter of interest, $\delta_{m}$, captures the effect of progressivity on income and consumption inequality. According to hypotheses $\mathrm{H} 1$ and $\mathrm{H} 2$, we expect $\delta_{m=n}<0$ and that $\left|\delta_{m=n}\right|$ is larger in countries with pro-poor redistributive policies. While our decompositional framework says very little about the sign of $\delta_{m=c}$, our two main hypotheses imply $\delta_{m=n}-$ $\delta_{m=c}<0(\mathrm{H} 3)$ and that this differential effect increases with tax evasion (H4). We use the baseline specification in equation (13) to test $\mathrm{H} 1$ before extending the model to test the remaining three hypotheses.

\subsection{Identification Issues}

There are several econometric issues that have to be addressed before we can test these hypotheses. To begin with, our measure of structural progressivity is likely to be endogenous for multiple reasons. First, the error term can be correlated with structural progressivity due to reverse causality. The political economy literature has long established a reverse relationship between income inequality and taxes (Meltzer and Richard, 1981; Persson and Tabellini, 2002; Borge and Rattso, 2004). Also, much of the empirical work that examines the effect of income inequality on economic growth argues that inequality affects growth through its effect on taxes and redistribution, (Perotti, 1992; Persson and Tabellini, 2002; Barro, 2000; Milanovic, 2000). This reverse causality implies that OLS estimation of $\delta$ is likely to be biased towards zero.

Second, the use of fixed effects is problematic given the limited within variation in the dependent variable for some countries; the GINI data are mostly sparse for a number of countries in our sample. ${ }^{24}$ To the extent that constant country characteristics are correlated with the error term, omitted fixed effects create an endogeneity bias.

Finally, structural progressivity is an estimated parameter with associated standard errors, which can lead to attenuation bias in the estimated coefficients, assuming standard errors follow the properties of the classical error-in-variables problem.

\footnotetext{
${ }^{24}$ Some countries either have one income base or they have both, but only for some years. Furthermore, there are a number of countries for which GINI data is only available for few years.
} 
We address these endogeneity issues by exploiting the spatial correlation in tax rates among neighboring countries to create instrumental variables (IVs) (Lee and Gordon, 2005). There are several channels through which this spatial correlation might arise. First, PIT rates will be correlated if countries actively compete for the PIT base; this is especially true for high skilled labor (Kleven, Landais and Saez, 2010; Egger and Radulescu, 2009). Second, the adoption of successful policies previously implemented by neighboring countries can lead to spatial correlation; this may be termed as policy diffusion (Whalley, 1990). Finally, spatial correlation in tax rates can arise as a result of yardstick competition if voters are able to pressure policy makers to adopt policies similar to that of neighboring countries in an effort to win re-election (Besley and Case, 1995).

We first construct IVs by assigning each contiguous neighbor an equal weight and calculating the mean of various tax progressivity measures for the reference country's neighbors. Theoretically, we require tax variables in country $i$ to be correlated with tax variables in neighboring country $j$ and orthogonal to the error term in equation (13). While the strength of the correlation can be established empirically (see discussion section 4.2), we must rely on intuitive arguments to support the orthogonality condition. For example, one may argue that an inflow of the PIT base in response to higher tax rate in neighboring countries will cause neighbors' tax rate to have a direct effect on inequality in country $i$, thus violating the orthogonality condition. ${ }^{25}$ However, the level of migration required for this to affect the orthogonality condition in any meaningful way likely outweighs observed flows of labor between countries. For example, according to the OECDs International Migration Outlook (2011) (OECD, 2011), net migration in selected OECD countries peaked at approximately 0.3 percent of total resident population in the 2001-2006 period. Therefore, we do not believe this to be a major concern for identification.

Another potential concern is the possibility that tax policy in neighboring countries and inequality in a given country are affected by common shocks, which may violate the

\footnotetext{
${ }^{25}$ For example, if the rich move enmasse to country $i$ in response to higher tax rates in their home country, then this might increase inequality in country $i$.
} 
orthogonality condition. We address this concern by both controlling for potential common shocks and using alternative IVs. In robustness checks, we control for average macroeconomic characteristics of neighboring countries (such as output and inflation) as a proxy for common shocks and find that our results hold. Alternative IVs include the one-year lag of neighbors' progressivity, and average progressivity measures for "neighbors of the neighbors", which represent the next layer of countries in the spatial dimension. Allowing the IVs to be based on neighbors from different points in space and time should help to break correlation between the IVs and the error term. We also use an indicator of complexity of neighboring countries' tax systems as an additional IV in some specifications. As indicated above, reverse causality implies OLS will be biased towards zero. Therefore, this bias works in our favor; at the very least, OLS should yield lower bound estimates

In an effort to minimize bias due to omitted fixed effects, we control for a variety of country characteristics. We include the country size measured as log of population, cultural background proxied by country's dominant religion, average inflation rate, and one-year lagged log of per capita GDP in quadratic form (see Appendix Table 8 for variable definitions). Inflation is included to account for the possible equalizing effect of price stability on the distribution of income (Minarik, 1979; Bulr, 2001). The quadratic GDP term is added to account for the existence of the Kuznets Curve which postulates there is a non-linear (inverted U) relationship between income inequality and per capita GDP. If it exists, we expect a positive coefficient on the linear term and a negative coefficient on the quadratic term. We also control for financial development since a well developed financial sector is likely correlated with both progressivity (Gordon and Li, 2007, 2009) and inequality (Mookerjee and Kalipioni, 2010; Law and Tan, 2009; Clarke, Xu and Zou, 2006). ${ }^{26}$ In addition to reducing omitted variable bias, financial development also allows us to control for access to consumption smoothing mechanisms. This is especially important for hypotheses H3 and

\footnotetext{
${ }^{26}$ We use the ratio of deposit money bank assets to all bank assets (central bank plus money bank) as our primary measure of financial development (Beck, Demirg-Kunt and Levine, 2000), and financial sector deposit as a share of GDP and interest rate spread as alternative measures in robustness checks.
} 
H4 since access to consumption smoothing mechanisms implies the variation in consumption inequality is likely to be systematically different from that of income inequality. As a result, the differential effect estimated in hypotheses H3 and H4 may be partly due to consumption smoothing rather than evasion. ${ }^{27}$

Another econometric issue is related to sample selection. High and upper middle income countries are over-represented in the reported net income GINI sample, but under represented in the consumption inequality GINI sample. For example, rich and upper middle income countries account for approximately 70 percent of net income GINI, but only 30 percent of consumption GINI in the estimation sample. Ignoring this source of non-randomness in the sample implies results will be biased.

We create sample probability weights to correct this sample selection issue. First, we divide the whole universe of independent countries in a given year into 3 equal groups by population and 4 equal groups by per capita GDP (in 1990 USD). This gives us a total of 12 population-GDP cells $(3 x 4)$ for which we calculate the number of countries in the general population in a given year $\left(N P_{t}\right)$. Then, for each income base separately, we calculate the number of countries in our estimation sample that is in each population-GDP cell in a given year $\left(N S_{t}\right)$. The ratio $\frac{N S_{t}}{N P_{t}}$ is the probability that a given country observation (for a given income base) is included in the estimation sample. For example, a ratio of $\frac{1}{5}$ means that only 20 percent of the world countries from a specific cell are included in the estimation sample in a given year. The inverse of this probability, which varies from 1-24 with a mean of 3.75, allows us to correct for the over (under) sampling of income GINIs among high (low) income countries when testing $\mathrm{H} 1$ and $\mathrm{H} 2 .^{28}$

We present empirical results for each hypothesis starting with hypothesis H1 in the next section.

\footnotetext{
${ }^{27}$ We also control for corporate tax rate and value added tax rates, separately, and find that they do not affect our conclusions. These results are available upon request.

${ }^{28}$ Specifications with multiple income bases are estimated with the following weight; $\frac{1}{n} \frac{N P_{t}}{N S_{t}}$, where $\frac{1}{n}$ is the inverse of the number of GINIs that appear in the data for each country year. This weight corrects for the fact that country-years with multiple income bases receive greater weight relative to country-years with only one income base.
} 


\subsection{Results for Observed Income Inequality}

We test hypothesis $\mathrm{H} 1$ by estimating equation (13) with $m=n$ and six measures of progressivity: the top statutory PIT rate, MRP, ARP, ARP-bottom, ARP-middle, and ARP-top. The results are reported in Table 2 where each column reports results for a different measure of progressivity. For presentation purposes, we chose neighbors' ARP-middle as our primary IV. Because this IV passes all the validity tests in practically every model we estimate, we use it in all models, thus maintaining comparability across the reported results. We use other IVs in robustness checks.

Panel A starts with a summary of the first stage results obtained from estimating our baseline model with ARP-middle as the IV. The estimated coefficient on the instrument is statistically different from zero at the 1 percent level across model specifications, indicating that the IV is strongly correlated with our endogenous variable. This conclusion is supported by the relatively large $F$ values for the excluded instrument, which allows us to reject the null that the instrument has no explanatory power in the first stage models. Finally, we reject the null that first stage equations are under-identified based on results from the Kleibergen and Paap lagrange multiplier under-identification test (Kleibergen and Paap, 2006). Together, these first stage results provide evidence that ARP-middle is well suited as an IV for our purposes.

The second stage results presented in Panel A indicate that progressivity has a statistically significant negative effect on reported income inequality. For example, a one percentage point increase in the top statutory PIT rate reduces the GINI by 0.95 points, ceteris paribus. A similar negative, but larger effect is found for each of the structural progressivity measures. In particular, a 1 unit increase in either MRP or ARP reduces the GINI coefficient by 3.2 points, which is about 30 percent of a standard deviation from the mean GINI coefficient in our estimation sample. ${ }^{29}$

\footnotetext{
${ }^{29}$ Table 9 in appendix D presents results for the complete OLS and IV specification of the baseline model with MRP and ARP as measures of progressivity. The OLS estimates of progressivity are negative and statistically significant in ARP specification, but they are much smaller than the IV estimates, as implied
} 
Another important finding in Table 2 is that changes in ARP-bottom has a smaller impact on income inequality compared to changes in ARP-top, i.e., increasing progressivity at the top of the income scale is a more effective method of reducing inequality in observed income. The estimated effect ranges from -1.7 for ARP-bottom to -7 for ARP-top. This result is expected given our discussion in section 2.2 that compares two channels through which progressivity may be increased: increase in the top rates or decrease in bottom rates. By comparing equations (4) and (5), it can be shown that $\left|\frac{\partial I^{o}}{\partial \tau_{p}}\right|<\left|\frac{\partial I^{o}}{\partial \tau_{r}}\right|$ under the plausible assumption that the rich has a higher combined productivity and evasion response than the poor $\left(\left|Y_{r}^{*^{\prime}}-E_{r}^{\prime}\right|>\left|Y_{p}^{*^{\prime}}-E_{p}^{\prime}\right|\right)$. Consistent with our decompositional framework, the estimates in Panel A of Table 2 (and subsequent tables) indicate a significantly higher inequality response to progressivity resulting from changes at the top of the income scale compared to rate changes in the lower tail of the income scale.

The above findings are supported by several modifications to the model. First, we reestimate equation (13) with an alternative $Z$ vector and report the results in Panel B of Table 2. The alternative $Z$ vector replaces inflation rate with fluctuations in exchange rate, and uses two alternative measures of financial development; financial system deposits to GDP ratio (Beck, Demirg-Kunt and Levine, 2000) and IMF interest rate spread (lending rate minus deposit rate). Controlling for these alternative variables does not change our qualitative results. Estimates of $\delta_{n}$ remain negative, economically meaningful, and are statistically different from zero. ${ }^{30}$

The remaining modifications focus on the robustness of the chosen IV. First, we re-estimate our baseline model with two IVs, ARP-middle and complexity in neighboring countries and report the results in Panel $\mathrm{C}$ of Table 2. Complexity is a time-varying index

in section 4.1. The other coefficients are mostly consistent with expectations. For example, the Kuznets hypothesis is confirmed though not statistically significant in the IV model with ARP; there is a strong negative association between the inequality and financial development; inequality tend to be lower in countries with no dominant religion (many former socialist countries are among them) with mixed results for other religion groups; and gross income inequality is higher than net income inequality.

${ }^{30} \mathrm{We}$ also control for the standard value added tax rate and corporate income tax rate, separately, and find that the results continue to hold. These results are available upon request. 
that summarizes several observable dimensions of the PIT schedule, including the complexity of allowances and tax credits, the use of multiple tax schedules, non-standard tax formulas, local taxes, national surtaxes, and the number of PIT brackets (Sabirianova Peter, Buttrick and Duncan, 2010). Given the components of our complexity index, we expect it to be positively correlated with progressivity. Again, first stage diagnostics indicate the IVs are strongly correlated with the endogenous variable and that the model is not underidentified. Furthermore, since we use two instruments, we implement the Sargan-Hansen over-identification test and find that we cannot reject the null that the orthogonality conditions for the instruments are satisfied. More importantly, the second stage results confirm our earlier findings.

Second, we use the one year lag of neighbors' ARP-middle, $\bar{P}_{i, t-1}^{n}$, as our IV to account for the possibility that countries do not adjust their tax rates in the same year as their neighbors. The results presented in Panel A of Table 3 indicate that our results do not change when lagged IV is used. Third, we define our instrumental variable, ARPmiddle, using the neighbors of a country's neighbors, $\bar{P}_{i, t}^{n n}$, where $n n$ represents the next tier of non-contiguous countries in the spatial dimension. This approach should strengthen our assumption that the IV is exogenous. It is possible, for instance, that migration from a country's contiguous neighbors might increase because of the neighbors' tax policy, which implies that the country's tax policy and inequality may be jointly impacted by neighbors' tax policy. Using the "neighbors of neighbors" IV would reduce these concerns. The model with this IV is presented in Panel $\mathrm{B}$ of Table 3 . We note that in some models with $\bar{P}_{i, t}^{n n}$, the correlation between $P_{i, t}$ and $\bar{P}_{i, t}^{n n}$ is smaller than the correlation between $P_{i, t}$ and $\bar{P}_{i, t}^{n}$ (as shown by smaller F statistics for excluded instruments), which may explain higher standard errors. However, the estimated inequality responses are all statistically significant at the 10 percent level and similar in magnitude to our baseline specification in Panel A of Table 2.

We acknowledge that our IV estimates reflect the local average treatment effect (LATE) of the progressivity on observed income inequality, and that the inequality response 
may not be same for every country, i.e., there is an underlying distribution of $\delta_{i}^{\prime} s$ that may vary with certain country characteristics. For example, as we show in subsequent sections, the inequality response is estimated to be higher in absolute value in countries with more developed democratic and legal institutions. If countries' reaction to the instrument depends on their $\delta_{i}$, the LATE estimate of inequality response might be sensitive to the choice of IVs (see Imbens and Angrist, 1994). For instructive purposes, we re-estimate the baseline model using ARP-bottom and ARP-top in neighboring countries as IVs (Panel C of Table 3) and find that the magnitude of the inequality response varies with the instruments. The estimated coefficient $\delta_{n}$ is largest when ARP-bottom is the IV and smallest when ARP-top is the IV. This result implies countries that increase their progressivity in response to a decrease in neighbors' bottom rates tend to have relatively higher inequality response, while countries that change their progressivity in response to an increase in neighbors' top rates tend to have relatively lower inequality response. ${ }^{31}$ For this reason, despite a seemingly large variety of valid instruments available to us, the LATE considerations favor more middle-ground instruments, such as ARP-middle, that is likely to affect all countries, thus producing estimates closer to the average treatment effect.

\subsection{Role of Democratic Institutions}

The effect of progressivity on observed income inequality, though shown to be unambiguously negative, may be affected by the redistribution policy of the government. Pro-rich redistribution in the presence of rising progressivity may cause the estimated effect of progressivity to be smaller than it actually is (in absolute value). We therefore expect progressivity to be more effective in economic environments conducive to pro-poor redistribution. In order to test this hypothesis, we extend the baseline equation for $m=n$ to include an interaction

\footnotetext{
${ }^{31}$ One possible explanation for this finding is evasion. Consider high evading countries, for example. We show in subsequent sections that these countries have relatively small $\delta \mathrm{s}$. It is reasonable to assume that high evading countries are also more likely to respond to a decrease in neighbors' ARP-top than low evading countries, since the potential benefits from greater compliance are greater for high evading countries. Therefore, because the high evaders comprise a relatively larger share of responders when ARP-top changes and have smaller $\delta$ s, the estimated effect on inequality is smaller when ARP-top is used as IV.
} 
term between the progressivity measures and democratic institutional variables. We drop subscript $n$ for convenience. In other words, we estimate the following model:

$$
I_{i t}=\beta_{0}+\delta_{0} G_{i t}+\delta_{1} P_{i t}+\delta_{2} P_{i t} * G_{i t}+\beta_{1} Z_{i t}+\beta_{2} W_{i t}+\zeta_{t}+\epsilon_{i t},
$$

where $G_{i t}$ is an indicator of pro-poor redistribution; all other variables are as defined above. The challenge in estimating equation (14) is finding a measure of pro-poor redistribution. Since we know of no such measure, we use variables we believe are strongly correlated with pro-poor redistribution. In particular, pro-poor policies are more likely to be implemented in countries with stronger democratic institutions that give people a voice in their political and economic governance to ensure liberty and equality.

Theoretical arguments for a positive relationship between democracy and pro-poor redistribution come from the median voter hypothesis. According to this hypothesis, the median voter votes for higher tax progressivity and greater redistribution as income inequality rises (Meltzer and Richard, 1981; Persson and Tabellini, 2002). Since the ability to vote requires some kind of democratic process, the median voter hypothesis implies a positive link between democracy and pro-poor redistribution. In other words, the more democratic the political process, the more likely it is that the median voter will have some influence over policy making, which implies greater pro-poor redistribution (Gradstein, Milanovic and Ying, 2001).

We use two institutional variables to proxy for the extent to which pro-poor redistribution exists in each country; political rights and civil liberties. Both variables are from Freedom House and are rated on a scale from 1 to 7 , with the highest value indicating no liberty or rights. Given hypothesis $\mathrm{H} 2$, we expect the coefficient on the interaction term $\delta_{2}$ to be positive. The coefficient estimates using political rights and civil liberty are reported in Table 4. We show results with ARP-middle of contiguous neighbors and its interaction with either political rights or civil liberty as IVs. First stage diagnostics indicate the models are not under-identified. Using lagged ARP-middle and ARP-middle for neighbors of neighbors 
as IVs produce similar results not shown here.

The estimates indicate that progressivity has a greater equalizing effect in countries with greater access to political rights and civil liberties. This is demonstrated more clearly in Figure where we plot the marginal effect of ARP against the political rights variable as estimated in the ARP column of Table 5. The effect is negative and statistically significant at the average political rights score of 2 , approximately zero at political rights scores between

3 and 4 , and positive for countries with very limited access to political rights (political scores above 4$)$.

These results show that using progressivity as a means of equalizing income may not be the best policy to implement in environments that offer little in the way of propoor redistribution. This further implies that equalizing the distribution of income via personal income taxes require not only progressive tax structures, but also active pro-poor redistribution policies on the expenditure side of the budget.

\subsection{The Effect of Progressivity on Inequality in Consumption}

One of the main predictions of the decomposition framework is that changes in progressivity may affect true and observed income inequality differently and that the magnitude of the differential effect is increasing with the share of unreported income in the economy. This result is very important since it suggests that policies aimed at reducing income inequality may actually worsen the distribution of income and vice-versa. For example, if tax evasion is widespread and the evasion response to tax changes is large relative to the productivity response among the rich, then lower taxes on the rich would lead to higher observed inequality, but possibly lower inequality in actual (reported and hidden) after-tax income. Therefore, adoption of a linear PIT may not be as bad for inequality as one might expect under these circumstance.

This section of the paper tests hypotheses H3 and H4 by extending equation (13) to include interaction terms. Recall that equation (13) represents two regressions: reported 
income inequality on progressivity and consumption inequality on progressivity when $m=n$ and $m=c$, respectively. ${ }^{32}$ The first step in testing hypotheses H3 and H4 is to combine these two models to create the following specification:

$$
I_{i t m}=\beta_{0}+\delta_{0} N_{i t}+\delta_{c} P_{i t}+\left(\delta_{n}-\delta_{c}\right) P_{i t} * N_{i t n}+\beta_{1} Z_{i t}+\beta_{2} W_{i t}+\zeta_{t}+\epsilon_{i t m}
$$

where $N$ is a dummy variable (=1 if reported net income) and all other variables are as defined previously. The coefficient $\delta_{n}-\delta_{c}$ tells us if the effect of progressivity on reported net income differs from that on consumption and is expected to be negative. ${ }^{33}$ In addition to being negative, hypothesis $\mathrm{H} 4$ tells us that the magnitude of the difference increases with tax evasion. We therefore extend equation (15) to account for this possibility by first assuming there are two types of countries: those with evasion and those without evasion. One might consider estimating equation (15) separately for each type of country or pooling data for both types of countries and estimating one regression. We implement the latter strategy by estimating the following 3-way interaction model:

$$
\begin{aligned}
I_{i t m}= & \beta_{0}^{H}+\beta_{1} Z_{i t}+\beta_{2} W_{i t}+\left(\beta_{0}^{L}-\beta_{0}^{H}\right) E^{L}+\delta_{0}^{H} N_{i t}+\left(\delta_{0}^{L}-\delta_{0}^{H}\right) N_{i t} * E^{L}+ \\
& \delta_{c}^{H} P_{i t}+\left(\delta_{c}^{L}-\delta_{c}^{H}\right) P_{i t} * E^{L}+\left(\delta_{n}^{H}-\delta_{c}^{H}\right) P_{i t} * N_{i t}+ \\
& \left(\left(\delta_{n}^{L}-\delta_{c}^{L}\right)-\left(\delta_{n}^{H}-\delta_{c}^{H}\right)\right) P_{i t} * N_{i t} * E^{L}+\zeta_{t}+\epsilon_{i t},
\end{aligned}
$$

which we re-write as:

$$
\begin{aligned}
I_{i t m}= & \gamma_{0}+\beta_{1} Z_{i t}+\beta_{2} W_{i t}+\gamma_{1} E^{L}+\gamma_{2} N_{i t}+\gamma_{3} N_{i t} * E^{L}+\gamma_{4} P_{i t}+ \\
& \gamma_{5} P_{i t} * E^{L}+\gamma_{6} P_{i t} * N_{i t}+\gamma_{7} P_{i t} * N_{i t} * E^{L}+\zeta_{t}+\epsilon_{i t},
\end{aligned}
$$

where $E^{L}$ is a dummy variable (=1 if low evading country) and all other variables are as defined previously. Although $E^{L}$ is specified as a categorical variable, the same reasoning applies to a continuous measure of evasion. Our decompositional framework does not yield

\footnotetext{
${ }^{32}$ For comparability with consumption, we now focus on reported net income and exclude gross income from the analysis.

${ }^{33}$ We note that if consumption expenditures used in GINI estimates are disproportionately underreported among the rich, then the difference between consumption inequality and income inequality based on survey data will be smaller than the actual difference in inequality. This implies that the differential effect posited in hypothesis 3 based on true expenditures will be even bigger in absolute value than the effect we estimate. Our estimate in this case can be interpreted as a lower bound estimate.
} 
any clear predictions for $\gamma_{4}$ nor does it say much about $\gamma_{5}=\left(\delta_{c}^{L}-\delta_{c}^{H}\right)$; both may or may not be positive, although, we suspect $\gamma_{5}$ is more likely to be negative since progressivity should have a more equalizing effect on consumption in countries with relatively low levels of evasion. The key parameters of interest are $\gamma_{6}=\delta_{n}^{H}-\delta_{c}^{H}$, which shows the differential effect of progressivity on net-income vs. consumption inequality in high-evading countries and $\gamma_{7}=\left(\delta_{n}^{L}-\delta_{c}^{L}\right)-\left(\delta_{n}^{H}-\delta_{c}^{H}\right)$, which shows how this differential effect varies between high and low evading countries. Our a priori expectation is that $\gamma_{6}<0$ (H3) and $\gamma_{7}>0$ (H4).

Table 4 shows the IV estimates for three models: equation (13) for consumption-based GINIs; equation (15) for combined income and consumption GINIs; and equation (17) with the three-way interaction between progressivity, income base, and a law and order index. The latter is an assessment of the legal system by the International Country Risk Guide (ICRG) beginning year 1984; it is on the scale from 0 to 6 , with 0 representing the worst law and order. The results are shown for MRP and ARP using average ARP-middle in bordering countries as IVs. ${ }^{34}$ The direct effect of progressivity on consumption inequality reported in columns "Model 1" is negative, but statistically insignificant. Adding income-based GINIs to consumption-based GINIs in "Model 2" makes the coefficient on ARP statistically significant, but no sizeable differential effect between the two income bases is detected; the interaction term is small and not statistically different from zero.

However, there is reason to suspect that these results do not tell the whole story. In particular, we show in section 2.5 that the differential effect is likely dependent on evasion opportunities. If this is the case, then equation (17) is the more appropriate model. Results from this specification are presented in "Model 3" of Table 5 for the ICRG law and order index, and Table 6 for the ICRG law and order index, the ICRG corruption index, and an indicator for high income economies. The ICRG corruption index is on the same 0 to 6 scale as the law and order index, and represents risk assessment of political corruption over the

\footnotetext{
${ }^{34}$ The results are similar for the lagged ARP-middle in bordering countries as IV, except for the ARPbottom model where the 3-way interaction term retains the expected sign but becomes statistically insignificant. The "neighbors of neighbors" IV and its 3-way interactions, unfortunately, do not pass the validity tests in the first stage, thus hindering the inference of the second stage.
} 
1984-2005 period. We define high income economies as high or upper middle income countries according to the World Bank income classification system. Examination of the interaction terms reveals strong support for hypotheses H3 and H4. For a typical country in the sample, we find that progressivity has a much greater influence on net income-based GINIs than on consumption-based GINIs $\left(\gamma_{6}<0\right)(\mathrm{H} 3)$. The positive and statistically significant coefficient on $\gamma_{7}$ supports the hypothesis that this differential effect is more pronounced in economic environments conducive to tax evasion $(\mathrm{H} 4) .{ }^{35}$

For easier interpretation, we calculate marginal effects over the range of possible values of each institutional variable separately for consumption and net income inequality. Results for the law and order index with ARP as our measure of structural progressivity are presented in Panel B of Figure . The marginal effect on consumption is negative and economically meaningful for all values of the law and order index. However, it is only statistically different from zero for the law and order index greater than 4.5, which is the mean value of law and order in the estimation sample. Similarly, the marginal effect on net income is negative, economically large, and statistically different from zero for all values of the law and order index. More importantly, we observe a very large differential effect on net income inequality (relative to consumption inequality) at low levels of institutional quality. This differential effect declines as the law and order score increases and the gap is approximately 1.5 point at the mean.

We also find that the differential effect $\gamma_{6}$ and its variation with evasion $\gamma_{7}$ depend on the source of the change in progressivity. Changes in progressivity at the top of the tax schedule have a significantly larger effect on both coefficients than changes at the bottom of the schedule. The larger effect follows directly from our decompositional framework model

\footnotetext{
${ }^{35} \mathrm{An}$ alternative interpretation of our findings is that taxpayers do not adjust consumption if they suspect tax reforms are temporary. To the extent that temporary tax reforms are more likely to occur in countries with weak institutions, our results may simply be picking up this effect. To check for this explanation, we calculate three measures of the stability of PIT reform: the number of years for which a given top PIT rate remains unchanged; number of years since last change in top PIT rate; and the variance of top PIT rates in the last five years. After including these measures into our model, the results continue to hold. We also use these measures in place of the institutional variables and find that the sign of the interaction terms is not consistent with the story implied by $\mathrm{H} 4$. The results are available upon request.
} 
(see discussion in section 2.3). This result implies that compared to the bottom rates, changes in top rates are more likely to generate a bigger response gap between observed income inequality and consumption inequality in both high- and low-evading countries, with the latter group having a higher differential response.

\section{Conclusions}

We develop a decomposition framework that yields four testable hypotheses about the relationship between tax progressivity and income inequality. First, we show that increased structural progressivity of the PIT structure reduces observed income inequality (H1), especially in redistributive environments (H2). We also derive that structural progressivity has a differential effect on observed vs. actual income inequality (H3), and that the difference between the two effects is positively related to the spread of tax evasion in the economy $(\mathrm{H} 4)$.

The predictions from the decomposition framework are tested using time-varying measures of structural progressivity of national income tax systems. As predicted, we find that PIT progressivity reduces observed inequality in reported gross and net income and show that this negative effect on observed income inequality is particularly strong in countries with more developed democratic institutions. At the same time, we find a significantly smaller negative effect of PIT progressivity on true inequality, approximated by consumption-based measures of the GINI coefficient. We also establish that the effect of tax progressivity on consumption inequality can be positive, especially in countries with weak law and order that increase the likelihood of tax evasion. Finally, we find evidence that changing progressivity at the top of the tax schedule is more effective in reducing inequality than similar changes at the bottom of the income scale. Although not stated explicitly, this result is also consistent with our decompositional framework.

Our empirical analysis implies that the tradeoff between equity and efficiency does in 
fact exist. This follows from the negative relationship that we identify between progressivity and income inequality. The result suggests that as taxes become more efficient, via lower progressivity, observed income inequality tends to increase. This result by itself points to the importance of taking into account the equity effects of shifts in tax policy towards greater efficiency.

What we find particularly interesting, though, is that the cost of efficiency differs across country groups. Because tax evasion is so pervasive in developing countries, our results lead us to speculate that developing countries face much lower equity costs of efficiency. That is, to the extent that efficiency is achieved by lowering the progressivity of taxes, developing countries with their higher levels of tax evasion, lose a lot less in terms of equity than developed countries. If flatter taxes can reduce the size of the underground economy, then they may actually improve the distribution of income via the direct compliance response and via pro-poor redistribution of increased tax revenues from higher levels of compliance. Developed countries on the other hand, may not benefit much from this evasion effect due to higher tax compliance rates to begin with. This may possibly explain why flat taxes are relatively more popular in developing countries than developed countries.

These results have important policy implications, especially given the debate surrounding the implementation of flat taxes. One common argument is to say that a linear PIT, while efficient, will lead to greater levels of income inequality. Our results imply this need not be the case for all countries. While observed income inequality will likely increase following the implementation of a linear PIT, actual income inequality may not change and may even improve in countries that suffer from high levels of tax evasion. 
Table 1: Summay Statistics: GINI and Progressivity

\begin{tabular}{|c|c|c|c|c|c|}
\hline Income Base & 1981-1985 & 1986-1990 & 1991-1995 & $1996-2000$ & 2001-2005 \\
\hline & \multicolumn{5}{|c|}{ Panel A: Income Base } \\
\hline \multirow[t]{3}{*}{ Consumption } & 31.701 & 34.454 & 37.751 & 36.299 & 36.596 \\
\hline & $(6.37)$ & $(7.811)$ & $(11.249)$ & $(8.291)$ & $(7.012)$ \\
\hline & [31] & [64] & [94] & {$[154]$} & [139] \\
\hline \multirow[t]{3}{*}{ Gross income } & 38.806 & 40.672 & 41.929 & 41.100 & 38.575 \\
\hline & $(9.54)$ & $(9.587)$ & $(10.581)$ & $(9.379)$ & $(7.271)$ \\
\hline & {$[78]$} & [94] & {$[126]$} & [149] & [88] \\
\hline \multirow[t]{3}{*}{ Net income } & 29.514 & 32.775 & 34.847 & 35.696 & 31.217 \\
\hline & $(8.48)$ & $(10.452)$ & $(10.646)$ & $(10.914)$ & $(6.577)$ \\
\hline & {$[77]$} & [105] & [155] & [232] & {$[178[$} \\
\hline \multirow[t]{4}{*}{ Total } & 33.775 & 36.006 & 37.954 & 37.375 & 34.662 \\
\hline & $(9.64)$ & $(10.161)$ & $(11.175)$ & $(10.052)$ & $(7.548)$ \\
\hline & {$[186]$} & {$[263]$} & {$[375]$} & {$[535]$} & {$[405]$} \\
\hline & \multicolumn{5}{|c|}{ Panel B: Progressivity Measures } \\
\hline \multirow[t]{3}{*}{ Top PIT rate } & 53.159 & 45.789 & 38.710 & 36.083 & 32.833 \\
\hline & $(14.076)$ & $(15.072)$ & $(12.238)$ & $(10.944)$ & $(11.152)$ \\
\hline & [214] & [288] & [439] & [578] & {$[456]$} \\
\hline \multirow[t]{2}{*}{ MRP } & 8.013 & 6.611 & 5.829 & 5.560 & 5.512 \\
\hline & $(4.168)$ & $(3.927)$ & $(3.186)$ & $(3.081)$ & (3.177) \\
\hline \multirow[t]{2}{*}{ ARP } & 6.880 & 5.776 & 4.821 & 4.770 & 4.820 \\
\hline & $(4.094)$ & $(3.819)$ & $(3.065)$ & $(2.781)$ & $(2.628)$ \\
\hline \multirow[t]{2}{*}{ ARP-bottom } & 11.339 & 9.453 & 7.899 & 7.979 & 8.111 \\
\hline & $(8.087)$ & $(7.118)$ & $(6.116)$ & $(5.619)$ & $(5.070)$ \\
\hline \multirow[t]{2}{*}{ ARP-middle } & 5.924 & 5.115 & 4.130 & 4.057 & 4.053 \\
\hline & $(3.446)$ & $(3.400)$ & $(2.719)$ & $(2.599)$ & $(2.611)$ \\
\hline \multirow[t]{3}{*}{ ARP-top } & 3.856 & 3.126 & 2.789 & 2.624 & 2.618 \\
\hline & (2.044) & $(1.884)$ & $(1.582)$ & $(1.560)$ & (1.630) \\
\hline & {$[186]$} & [263] & {$[375]$} & {$[535]$} & {$[405]$} \\
\hline
\end{tabular}

Standard deviation in parentheses and number of observations in brackets. ARP and MRP are average and marginal tax rate progression for income between 0.4 to 4 times a country's per capita GDP, respectively. ARP bottom, middle and top are average tax rate progression for income between 0.4 to 2,1 to 3 , and 2 to 4 times a country's per capita GDP, respectively. 
Table 2: Effect of Progressivity on Income Inequality: IV estimates

\begin{tabular}{|c|c|c|c|c|c|c|}
\hline & \multirow{2}{*}{ Top Rate } & \multirow{2}{*}{ MRP } & \multirow{2}{*}{$\mathrm{ARP}$} & \multicolumn{3}{|c|}{$\mathrm{ARP}$} \\
\hline & & & & Bottom & Middle & Top \\
\hline \multicolumn{7}{|c|}{ Panel A: One IV } \\
\hline \multicolumn{7}{|l|}{ First stage diagnostics } \\
\hline IV1 - ARP-middle & $\begin{array}{l}1.778 * * * \\
(0.664)\end{array}$ & $\begin{array}{l}0.513^{* * *} \\
(0.171)\end{array}$ & $\begin{array}{l}0.508^{* * *} \\
(0.125)\end{array}$ & $\begin{array}{l}0.945^{* * *} \\
(0.213)\end{array}$ & $\begin{array}{l}0.382^{* * *} \\
(0.128)\end{array}$ & $\begin{array}{l}0.231^{* * * *} \\
(0.084)\end{array}$ \\
\hline Under ID - Pvalue & 0.018 & 0.007 & 0.001 & 0.000 & 0.008 & 0.012 \\
\hline F - Stat & $7.160^{* * *}$ & $9.003^{* * *}$ & $16.447^{* * *}$ & $19.629^{* * *}$ & $8.896^{* * *}$ & $7.493^{* * *}$ \\
\hline \multicolumn{7}{|l|}{ Second stage results } \\
\hline Progressivity & $\begin{array}{l}-0.945^{* *} \\
(0.428)\end{array}$ & $\begin{array}{l}-3.151^{* *} \\
(1.292)\end{array}$ & $\begin{array}{l}-3.180^{* * *} \\
(1.040)\end{array}$ & $\begin{array}{l}-1.710^{* * *} \\
(0.532)\end{array}$ & $\begin{array}{l}-4.230^{* * *} \\
(1.638)\end{array}$ & $\begin{array}{l}-7.008^{* *} \\
(3.128)\end{array}$ \\
\hline F - Stat & $4.656^{* * *}$ & $5.809^{* * *}$ & $9.582^{* * *}$ & $8.501^{* * *}$ & $8.241^{* * *}$ & $4.658^{* * *}$ \\
\hline \multicolumn{7}{|c|}{ Panel B: Alternative Z Vector } \\
\hline Progressivity & $\begin{array}{l}-0.897^{* *} \\
(0.401)\end{array}$ & $\begin{array}{l}-2.750^{* *} \\
(1.160)\end{array}$ & $\begin{array}{l}-2.934^{* * *} \\
(1.068)\end{array}$ & $\begin{array}{l}-1.617^{* * *} \\
(0.568)\end{array}$ & $\begin{array}{l}-3.861^{* *} \\
(1.641)\end{array}$ & $\begin{array}{l}-6.017^{* *} \\
(2.681)\end{array}$ \\
\hline \multicolumn{7}{|c|}{ Panel C: Two IVs } \\
\hline \multicolumn{7}{|c|}{ First stage diagnostics } \\
\hline IV1 - ARP-middle & $\begin{array}{c}1.090^{*} \\
(0.587)\end{array}$ & $\begin{array}{l}0.393^{* * *} \\
(0.152)\end{array}$ & $\begin{array}{l}0.368^{* * *} \\
(0.096)\end{array}$ & $\begin{array}{l}0.706^{* * *} \\
(0.164)\end{array}$ & $\begin{array}{c}0.244^{* *} \\
(0.109)\end{array}$ & $\begin{array}{c}0.182^{* *} \\
(0.078)\end{array}$ \\
\hline IV2 - Complexity & $\begin{array}{c}2.137^{*} \\
(1.020)\end{array}$ & $\begin{array}{c}0.383^{*} \\
(0.208)\end{array}$ & $\begin{array}{l}0.447^{* * *} \\
(0.172)\end{array}$ & $\begin{array}{l}0.764^{* *} \\
(0.332)\end{array}$ & $\begin{array}{l}0.441^{* * *} \\
(0.175)\end{array}$ & $\begin{array}{c}0.154 \\
(0.105)\end{array}$ \\
\hline Under ID - Pvalue & 0.058 & 0.025 & 0.002 & 0.001 & 0.027 & 0.042 \\
\hline F - Stat & $4.843^{* * *}$ & $5.580 * * *$ & $10.986^{* * *}$ & $12.380^{* * *}$ & $7.158^{* * *}$ & $4.395^{* * *}$ \\
\hline Hansen J - Pvalue & 0.570 & 0.738 & 0.885 & 0.773 & 0.694 & 0.686 \\
\hline \multicolumn{7}{|l|}{ Second stage results } \\
\hline Progressivity & $\begin{array}{l}-0.852^{* *} \\
(0.356)\end{array}$ & $\begin{array}{l}-3.278^{* *} \\
(1.332)\end{array}$ & $\begin{array}{l}-3.227^{* * *} \\
(1.085)\end{array}$ & $\begin{array}{l}-1.760^{* * *} \\
(0.573)\end{array}$ & $\begin{array}{l}-4.003^{* * *} \\
(1.495)\end{array}$ & $\begin{array}{l}-7.369 * * \\
(3.248)\end{array}$ \\
\hline F - Stat & $5.159^{* * *}$ & $5.633^{* * *}$ & $9.543^{* * *}$ & $8.268^{* * *}$ & $8.782^{* * *}$ & $4.444^{* * *}$ \\
\hline $\mathrm{N}$ & 1372 & 1223 & 1223 & 1223 & 1223 & 1223 \\
\hline
\end{tabular}

Robust standard errors adjusted for clustering at the country level are in parentheses; ${ }^{*}$ significant at $10 \%$; $* *$ significant at $5 \%$; ** significant at $1 \%$. Estimates are based on equation (13) with the dependent variable defined as GINI in gross or net income. The GINI is measured on a scale from 0 to 100 and has a mean of 36 with standard deviation of 10 in the estimation sample. The measure of structural progressivity is indicated by column titles. The following covariates are included in Panels A and C, but not shown: log of population, the quadratic function of the lagged log of GDP per capita, country's dominant religion, average inflation rate, the ratio of deposit money bank assets to all bank assets, time dummies, and a vector of auxiliary variables for the quality of GINI measures. The model in Panel B replaces inflation with fluctuations in exchange rate and deposit ratio with the interest rate spread and the share of financial deposits in GDP. See Table 9 for a complete specification. All models are estimated with sampling weights (see Section 4.1 for details on weighting procedure). $\mathrm{N}$ is the same in all panels. The diagnostic statistics in Panel B is similar to that in Panel A and not reported to preserve space. 
Table 3: Effect of Progressivity on Observed Income Inequality: Alternative IVs

\begin{tabular}{|c|c|c|c|c|c|c|}
\hline & \multirow{2}{*}{ Top Rate } & \multirow{2}{*}{ MRP } & \multirow{2}{*}{$\mathrm{ARP}$} & \multicolumn{3}{|c|}{$\mathrm{ARP}$} \\
\hline & & & & Bottom & Middle & Top \\
\hline & \multicolumn{6}{|c|}{ Panel A: IV (Lagged (t-1)) } \\
\hline \multirow[t]{2}{*}{ ARP-middle } & $-1.170 * * *$ & $-5.345^{* *}$ & $-4.646^{* * *}$ & $-2.275^{* * *}$ & $-6.961^{* *}$ & $-12.185^{* *}$ \\
\hline & $(0.453)$ & $(2.320)$ & $(1.522)$ & $(0.711)$ & $(3.013)$ & $(5.903)$ \\
\hline F - Stat (1st stage) & $8.284^{* * *}$ & $6.053^{* *}$ & $11.532^{* * *}$ & $14.086^{* * *}$ & $5.308^{* *}$ & $4.963^{* *}$ \\
\hline \multirow[t]{2}{*}{$\mathrm{N}$} & 1337 & 1195 & 1195 & 1195 & 1195 & 1195 \\
\hline & \multicolumn{6}{|c|}{ Panel B: IV (Neighbor of Neighbor) } \\
\hline \multirow[t]{2}{*}{ ARP-middle } & $-1.138^{* *}$ & $-4.064^{*}$ & $-3.224^{* * *}$ & $-1.462^{* * *}$ & $-5.516^{* *}$ & $-9.127^{*}$ \\
\hline & $(0.574)$ & $(2.103)$ & $(1.129)$ & $(0.478)$ & $(2.675)$ & $(5.276)$ \\
\hline F-Stat $\left(1^{\text {st }}\right.$ stage $)$ & $5.956^{* *}$ & $5.980^{* *}$ & $18.884^{* * *}$ & $24.361^{* * *}$ & $5.457^{* *}$ & $4.778^{* *}$ \\
\hline \multirow[t]{2}{*}{$\mathrm{N}$} & 1433 & 1282 & 1282 & 1282 & 1282 & 1282 \\
\hline & \multicolumn{6}{|c|}{ Panel C: IV (Contiguous Neighbor) } \\
\hline \multirow[t]{2}{*}{ MRP } & $-0.705^{* *}$ & $-2.472^{* *}$ & $-2.655^{* * *}$ & $-1.569 * * *$ & $-3.044^{* *}$ & $-5.577^{*}$ \\
\hline & $(0.355)$ & $(1.167)$ & $(1.022)$ & $(0.568)$ & $(1.270)$ & $(2.853)$ \\
\hline \multirow[t]{2}{*}{ ARP } & $-1.149^{* *}$ & $-4.434^{* * *}$ & $-3.704^{* * *}$ & $-1.788^{* * *}$ & $-5.491^{* * *}$ & $-10.180^{* *}$ \\
\hline & $(0.447)$ & $(1.706)$ & $(1.000)$ & $(0.444)$ & $(1.884)$ & $(4.460)$ \\
\hline \multirow[t]{2}{*}{ ARP-bottom } & $-1.475^{* * *}$ & $-6.949^{* *}$ & $-4.396^{* * *}$ & $-1.865^{* * *}$ & $-8.080 * * *$ & $-16.626^{*}$ \\
\hline & $(0.562)$ & $(3.072)$ & $(1.085)$ & $(0.411)$ & $(3.054)$ & $(8.838)$ \\
\hline \multirow[t]{2}{*}{ ARP-middle } & $-0.945^{* *}$ & $-3.151^{* *}$ & $-3.180 * * *$ & $-1.710^{* * *}$ & $-4.230 * * *$ & $-7.008^{* *}$ \\
\hline & $(0.428)$ & $(1.292)$ & $(1.040)$ & $(0.532)$ & $(1.638)$ & $(3.128)$ \\
\hline \multirow[t]{2}{*}{ ARP-top } & $-0.645^{*}$ & $-2.276^{* *}$ & $-2.480^{* *}$ & $-1.496^{* * *}$ & $-2.758^{* *}$ & $-5.148^{*}$ \\
\hline & $(0.348)$ & $(1.120)$ & $(1.008)$ & $(0.572)$ & (1.199) & $(2.735)$ \\
\hline $\mathrm{N}$ & 1372 & 1223 & 1223 & 1223 & 1223 & 1223 \\
\hline
\end{tabular}

Robust standard errors adjusted for clustering at the country level are in parentheses; * significant at $10 \%$; ** significant at $5 \%$; *** significant at 1\%. Estimates are based on equation (13) with the dependent variable defined as GINI in gross or net income. Each specification is similar to that in panel A of Table 2, but only progressivity coefficients in the second stage are reported. The measure of structural progressivity is indicated by column titles. IV in Panels A and B is ARP-middle of contiguous neighbors. IVs in panel B are indicated by the name of each row. We use the 5 closest neighbors for island economies based on the distance between capitals. All models are estimated with sampling weights (see Section 4.1 for details on weighting procedure) and pass the Kleibergen and Paap lagrange multiplier under-identification test. The F-test for significance of IVs in the first stage is statistically different from zero in all models. 
Table 4: Role of Redistribution

\begin{tabular}{|c|c|c|c|c|c|c|}
\hline & \multirow{2}{*}{ Top Rate } & \multirow{2}{*}{ MRP } & \multirow{2}{*}{$\mathrm{ARP}$} & \multicolumn{3}{|c|}{ ARP } \\
\hline & & & & Bottom & Middle & Top \\
\hline & \multicolumn{6}{|c|}{ Panel A: Political Rights } \\
\hline \multirow[t]{2}{*}{ Progressivity } & $-1.118^{* *}$ & $-6.306^{* *}$ & $-6.489 * * *$ & $-3.622 * * *$ & $-8.411^{* * *}$ & $-14.758^{* *}$ \\
\hline & $(0.484)$ & $(2.511)$ & $(2.073)$ & $(1.292)$ & $(3.124)$ & $(6.795)$ \\
\hline \multirow[t]{2}{*}{ Interaction } & $0.191^{* *}$ & $1.807^{* * *}$ & $2.033^{* * *}$ & $1.223^{* *}$ & $2.495^{* * *}$ & $4.209^{* *}$ \\
\hline & $(0.089)$ & $(0.668)$ & $(0.652)$ & $(0.491)$ & $(0.890)$ & $(1.804)$ \\
\hline Under ID - Pvalue & 0.006 & 0.006 & 0.000 & 0.001 & 0.004 & 0.019 \\
\hline \multirow[t]{2}{*}{ F - Stat } & $5.292^{* * *}$ & $7.223^{* * *}$ & $9.585^{* * *}$ & $5.460 * * *$ & $6.353^{* * *}$ & $5.646^{* * *}$ \\
\hline & \multicolumn{6}{|c|}{ Panel B: Civil liberties } \\
\hline \multirow[t]{2}{*}{ Progressivity } & $-1.487^{* *}$ & $-9.142^{* *}$ & $-8.392 * * *$ & $-4.770 * *$ & $-11.617^{* *}$ & $-21.995^{* *}$ \\
\hline & $(0.601)$ & $(3.584)$ & $(2.854)$ & $(1.931)$ & $(4.689)$ & $(10.198)$ \\
\hline \multirow[t]{2}{*}{ Interaction } & $0.337^{* *}$ & $2.827^{* * *}$ & $2.513^{* * *}$ & $1.496^{* *}$ & $3.547^{* *}$ & $6.836^{* *}$ \\
\hline & $(0.140)$ & $(1.065)$ & $(0.864)$ & $(0.667)$ & $(1.403)$ & $(3.051)$ \\
\hline Under ID - Pvalue & 0.002 & 0.006 & 0.000 & 0.003 & 0.009 & 0.020 \\
\hline F - Stat & $4.616^{* * *}$ & $5.818^{* * *}$ & $7.153^{* * *}$ & $4.563^{* * *}$ & $5.248^{* * *}$ & $4.413^{* * *}$ \\
\hline $\mathrm{N}$ & 1372 & 1223 & 1223 & 1223 & 1223 & 1223 \\
\hline
\end{tabular}

Robust standard errors adjusted for clustering at the country level are in parentheses; ${ }^{*}$ significant at $10 \%$; ${ }^{* *}$ significant at $5 \%$; *** significant at $1 \%$. The dependent variable is GINI in gross or net income. Each model uses the same variables as in Panel A of Table 2 along with the specified institutional variable, but only progressivity and its interaction with the institutional variable are reported. The measure of structural progressivity is indicated by column titles. IV is ARP-middle of contiguous neighbors and its interaction with the specified institutional variable in both panels. We use the 5 closest neighbors for island economies based on the distance between capitals. All models are estimated with sampling weights (see Section 4.1 for details on weighting procedure) and pass the Kleibergen and Paap lagrange multiplier under-identification test (Under ID - Pvalue). Political rights and civil liberties are measured on a reverse scale 1 to 7 where 7 indicates no political rights or no civil liberties. $\mathrm{N}$ is the same in both panels. 
Table 5: Differential Effect of Progressivity on Inequality in Consumption and Observed Income

\begin{tabular}{|c|c|c|c|c|c|c|}
\hline & \multicolumn{3}{|c|}{ MRP } & \multicolumn{3}{|c|}{ ARP } \\
\hline & Model 1 & Model 2 & Model 3 & Model 1 & Model 2 & Model 3 \\
\hline $\mathrm{P}\left(\gamma_{4}\right)$ & $\begin{array}{l}-0.463 \\
(1.187)\end{array}$ & $\begin{array}{l}-2.212 \\
(1.393)\end{array}$ & $\begin{array}{c}2.695 \\
(1.928)\end{array}$ & $\begin{array}{l}-0.765 \\
(1.806)\end{array}$ & $\begin{array}{l}-2.874^{* *} \\
(1.422)\end{array}$ & $\begin{array}{c}0.959 \\
(2.597)\end{array}$ \\
\hline $\mathrm{P}^{*} \mathrm{Law}\left(\gamma_{5}\right)$ & & & $\begin{array}{l}-1.189^{* *} \\
(0.565)\end{array}$ & & & $\begin{array}{l}-0.789^{*} \\
(0.459)\end{array}$ \\
\hline $\mathrm{P}^{*} \mathrm{~N}\left(\gamma_{6}\right)$ & & $\begin{array}{l}-0.937 \\
(0.685)\end{array}$ & $\begin{array}{l}-8.757^{* * * *} \\
(3.368)\end{array}$ & & $\begin{array}{l}-0.490 \\
(0.639)\end{array}$ & $\begin{array}{l}-9.304^{* * *} \\
(3.243)\end{array}$ \\
\hline $\mathrm{P}^{*} \mathrm{~N}^{*} \mathrm{Law}\left(\gamma_{7}\right)$ & & & $\begin{array}{l}1.712^{* * *} \\
(0.630)\end{array}$ & & & $\begin{array}{l}1.761^{* * *} \\
(0.552)\end{array}$ \\
\hline Law $\left(\gamma_{1}\right)$ & & & $\begin{array}{c}2.960 \\
(2.405)\end{array}$ & & & $\begin{array}{c}0.135 \\
(1.354)\end{array}$ \\
\hline $\mathrm{N}\left(\gamma_{2}\right)$ & & $\begin{array}{c}2.952 \\
(3.544)\end{array}$ & $\begin{array}{l}33.370^{* * *} \\
(12.868)\end{array}$ & & $\begin{array}{c}2.435 \\
(2.984)\end{array}$ & $\begin{array}{c}23.562^{* *} \\
(9.937)\end{array}$ \\
\hline $\mathrm{N}^{*} \operatorname{Law}\left(\gamma_{3}\right)$ & & & $\begin{array}{l}-7.064^{* *} \\
(2.959)\end{array}$ & & & $\begin{array}{l}-4.752^{* *} \\
(2.182)\end{array}$ \\
\hline Under ID - Stat & 7.106 & 10.165 & 7.126 & 5.078 & 10.319 & 8.348 \\
\hline Under ID - Pvalue & 0.008 & 0.001 & 0.008 & 0.024 & 0.001 & 0.004 \\
\hline Weak ID - Stat & 8.193 & 5.585 & 1.527 & 5.152 & 5.518 & 2.054 \\
\hline F - Stat & $7.669^{* * *}$ & $6.693^{* * *}$ & $8.591^{* * *}$ & $7.916^{* * *}$ & $12.111^{* * *}$ & $11.990 * * *$ \\
\hline Observation & 468 & 1185 & 1025 & 468 & 1185 & 1025 \\
\hline
\end{tabular}

Robust standard errors adjusted for clustering at the country level are in parentheses; * significant at $10 \%$; ** significant at $5 \%$; ** significant at 1\%. $P$ is progressivity, Law is law and order index, and $N$ is income base. The dependent variable is GINI in net income or expenditures/consumption. All models are estimated with sampling weights (see Section 4.1 for details on weighting procedure). Specifications in models 1, 2, and 3 are defined in equations (13), (15), and (16), respectively, but only coefficients of interest are reported. IVs are ARP-middle in bordering countries and its respective interactions. Model 1 uses consumption-based GINIs only. The law and order index is measured on a scale from 0 to 6 , with 0 representing the worst case. 
Table 6: Differential Effect of Progressivity on Inequality in Consumption and Observed Income

\begin{tabular}{|c|c|c|c|c|c|}
\hline & \multirow{2}{*}{ MRP } & \multirow{2}{*}{$\mathrm{ARP}$} & \multicolumn{3}{|c|}{ ARP } \\
\hline & & & Bottom & Middle & Top \\
\hline & \multicolumn{5}{|c|}{ Law and Order } \\
\hline \multirow{2}{*}{$\mathrm{P}^{*} \mathrm{~N}\left(\gamma_{6}\right)$} & $-8.757 * * *$ & $-9.304 * * *$ & $-5.104^{* *}$ & $-11.856^{* * *}$ & $-18.632^{* *}$ \\
\hline & $(3.368)$ & $(3.243)$ & $(2.205)$ & $(4.507)$ & $(8.005)$ \\
\hline \multirow[t]{2}{*}{$\mathrm{P}^{*} \mathrm{~N}^{*} \mathrm{Law}\left(\gamma_{7}\right)$} & $1.712^{* * *}$ & $1.761^{* * *}$ & $0.936^{* * *}$ & $2.417^{* * *}$ & $3.571^{* *}$ \\
\hline & $(0.630)$ & $(0.552)$ & $(0.351)$ & $(0.932)$ & $(1.488)$ \\
\hline Under ID - Stat & 7.126 & 8.348 & 4.948 & 3.693 & 5.823 \\
\hline Under ID - Pvalue & 0.008 & 0.004 & 0.026 & 0.055 & 0.016 \\
\hline \multirow[t]{2}{*}{ F - Stat } & $8.591^{* * *}$ & $11.990^{* * *}$ & $10.278^{* * *}$ & $9.021^{* * *}$ & $6.601^{* * *}$ \\
\hline & \multicolumn{5}{|c|}{ Corruption } \\
\hline \multirow[t]{2}{*}{$\mathrm{P}^{*} \mathrm{~N}\left(\gamma_{6}\right)$} & $-8.033^{* * *}$ & $-5.928 * *$ & -1.341 & $-8.892^{* *}$ & $-18.516^{* * *}$ \\
\hline & $(2.969)$ & $(2.989)$ & $(3.015)$ & $(4.481)$ & $(7.178)$ \\
\hline \multirow{2}{*}{$\mathrm{P}^{*} \mathrm{~N}^{*}$ Corruption $\left(\gamma_{7}\right)$} & $1.721^{* * *}$ & $1.366^{* * *}$ & 0.436 & $2.029^{* *}$ & $3.810^{* *}$ \\
\hline & $(0.601)$ & $(0.516)$ & $(0.472)$ & $(0.917)$ & $(1.483)$ \\
\hline Under ID - Stat & 6.343 & 5.449 & 2.577 & 3.835 & 5.040 \\
\hline Under ID - Pvalue & 0.012 & 0.020 & 0.108 & 0.050 & 0.025 \\
\hline \multirow[t]{2}{*}{ F - Stat } & $5.961^{* * *}$ & $10.523^{* * *}$ & $11.520^{* * *}$ & $5.835^{* * *}$ & $4.142^{* * *}$ \\
\hline & \multicolumn{5}{|c|}{ High Income } \\
\hline \multirow[t]{2}{*}{$\mathrm{P}^{*} \mathrm{~N}\left(\gamma_{6}\right)$} & $-7.243^{* * *}$ & $-6.043^{* *}$ & -2.604 & $-10.433^{* *}$ & $-16.764^{* *}$ \\
\hline & $(2.803)$ & $(2.769)$ & $(1.774)$ & $(4.476)$ & $(6.958)$ \\
\hline \multirow[t]{2}{*}{$\mathrm{P}^{*} \mathrm{~N}^{*}$ High Income $\left(\gamma_{7}\right)$} & $7.960 * * *$ & $7.334^{* *}$ & $3.431^{*}$ & $12.324^{* *}$ & $17.925^{* *}$ \\
\hline & $(2.921)$ & $(3.048)$ & $(1.985)$ & $(5.014)$ & $(7.275)$ \\
\hline Under ID - Stat & 2.776 & 2.526 & 1.702 & 1.679 & 2.368 \\
\hline Under ID - Pvalue & 0.096 & 0.112 & 0.192 & 0.195 & 0.124 \\
\hline F - Stat & $7.992^{* * *}$ & $14.492^{* * *}$ & $13.706^{* * *}$ & $5.849 * * *$ & $5.432^{* * *}$ \\
\hline
\end{tabular}

Robust standard errors adjusted for clustering at the country level are in parentheses; * significant at $10 \%$; ** significant at $5 \%$; ** significant at $1 \%$. $\mathrm{P}$ is progressivity, Law is the law and order index, and $\mathrm{N}$ is a dummy for income-based GINIs. The dependent variable is GINI in net income or expenditures/consumption. All models are estimated with sampling weights (see Section 4.1 for details on weighting procedure). Each specification is similar to model 3 in Table 5 and defined in equation (16), but only coefficients of interest are reported. IVs are ARP-middle in bordering countries and its respective interactions. The law and order and corruptions indices are measured on a scale from 0 to 6 , with 0 representing the worst case. High Income $=1$ if high or upper middle income country according to World Bank classification. Number of observation=1025 in panels A and $\mathrm{B}$ and 1185 in panel $\mathrm{C}$. 


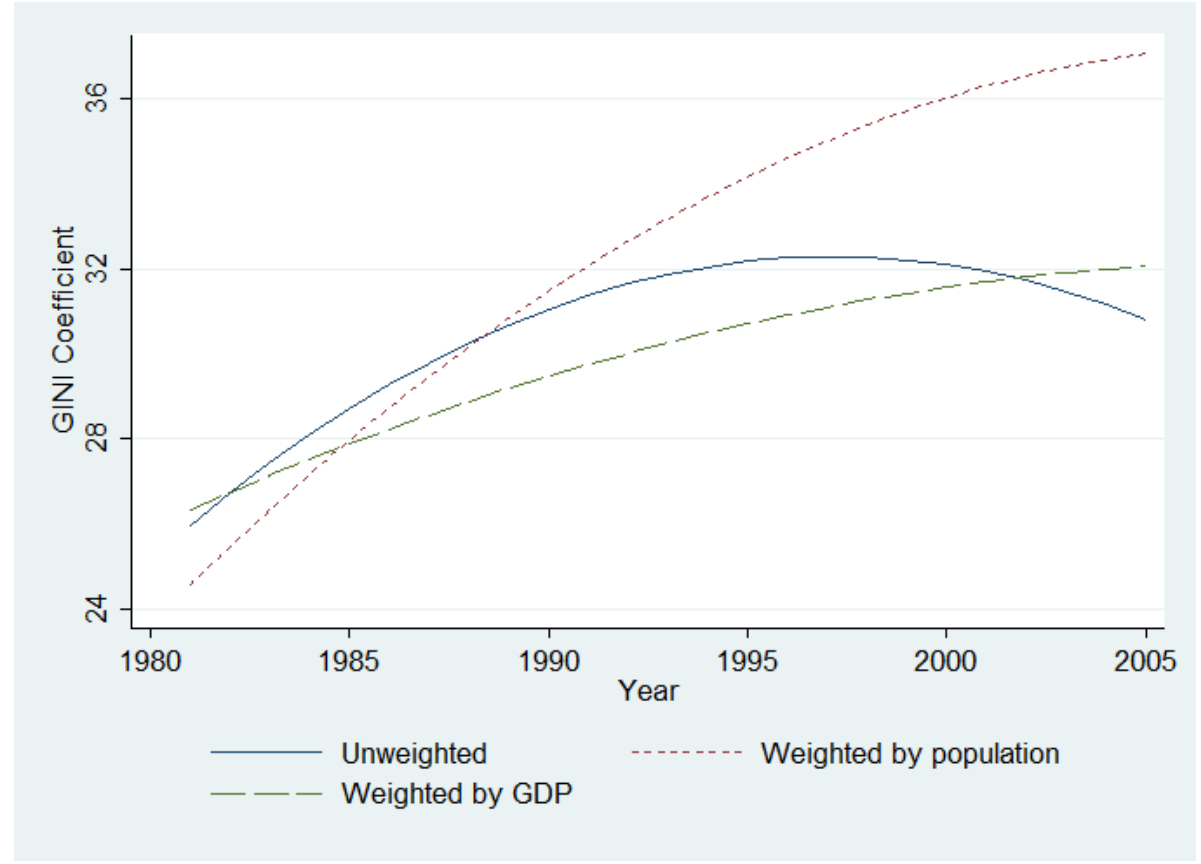

Figure 1: Global Trend in Income Inequality, 1981-2005

The trend in income inequality is obtained by regressing the GINI coefficient on a quadratic time trend, controlling for income base, area coverage, income adjustment, and World Bank income classification. 


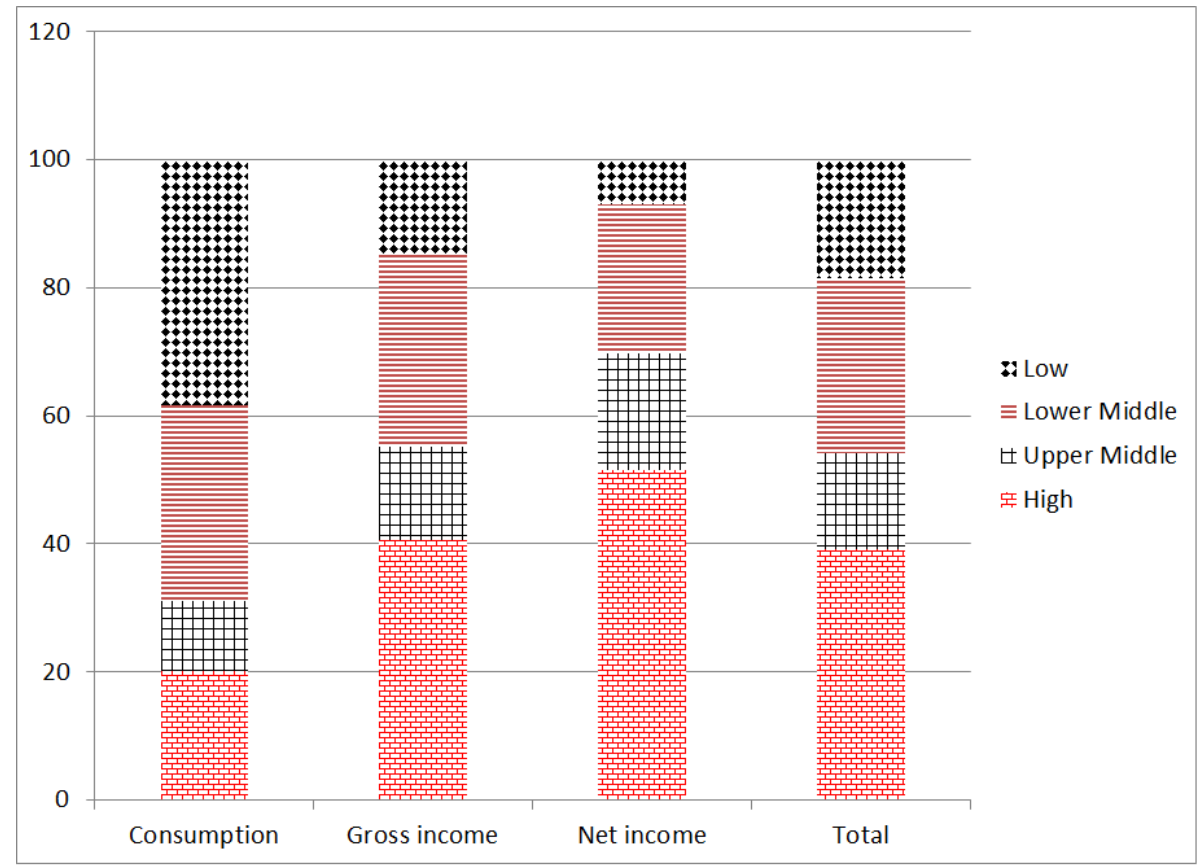

Figure 2: Sample Composition by Income Base

Reported is the share of observations that comes from each World Bank income class, by GINI income base. For example, High income countries account for approximately $20 \%$ and $50 \%$ of Consumption and Net Income GINIs, respectively. 

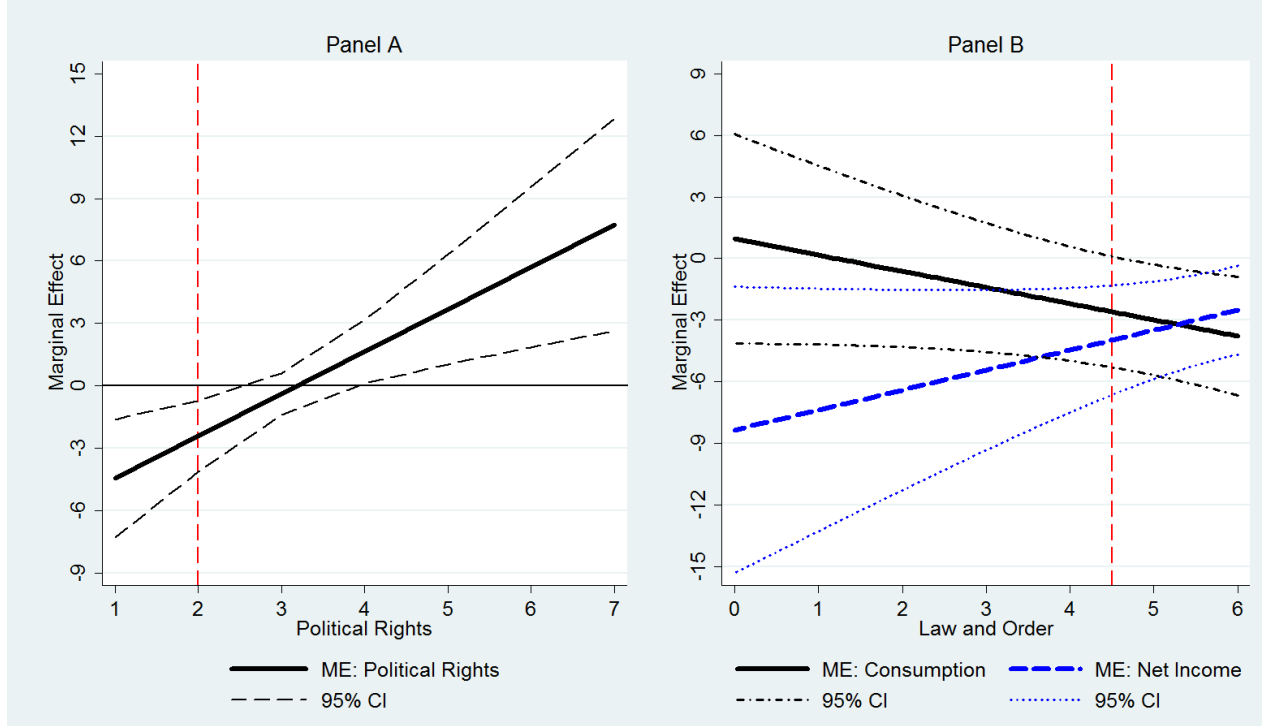

Figure 3: Marginal Effect of ARP1 on Inequality

Panel A: Marginal effects calculated using estimates in Panel A of Table 4. The red broken line indicates the mean of political rights in the estimation sample. Political rights is measured on a 7 point scale; 1 to 7 with 7 indicating no political rights.

Panel B: Marginal effects calculated using estimates in column 6 of Table 6 . The red broken line indicates the mean of the law and order index in the estimation sample $(=4.5)$. The law and order index is measured on a 7 point scale; 0 to 6 , with $0=$ worse law and order. The $95 \%$ confidence intervals indicate that the marginal effects for consumption are statistically significant for the law and order index greater than 4.5, while those for net income are significant for all values of the law and order index. 


\section{References}

Allingham, Michael, and Agnar Sandmo. 1972. "Income Tax Evasion: A Theoretical Analysis." Journal of Public Economics, 1(3-4): 323-338.

Atkinson, Anthony B., and Andrea Brandolini. 2001. "Promise and Pitfalls in the Use of "Secondary' Data-Sets: Income Inequality in OECD Countries as a Case Study." Journal of Economic Literature, 39(3): 771-99.

Barro, Robert J. 2000. "Inequality and Growth in a Panel of Countries." Journal of Economic Growth, 5(1): 5-32.

Beck, Thorsten, Asli Demirg-Kunt, and Ross Levine. 2000. "A New Database on Financial Development and Structure." World Bank Economic Review, 14(3): 597-605.

Besley, Timothy, and Anne Case. 1995. "Incumbent Behavior: Vote-Seeking, TaxSetting, and Yardstick Competition." The American Economic Review, 85(1): 25-45.

Blundell, Richard, Alan Duncan, and Costas Meghir. 1998. "Estimating Labor Supply Responses Using Tax Reforms." Econometrica, 66(4): 827-61.

Borge, Lars-Erik, and J.Jorn Rattso. 2004. "Income distribution and tax structure: Empirical test of the Meltzer-Richard hypothesis." European Economic Review, 48(4): 805826.

Bulr, Ales. 2001. "Income Inequality: Does Inflation Matter?" IMF Staff Papers, 48(1): 139-159.

Chetty, Raj. 2009. "Is the Taxable Income Elasticity Sufficient to Calculate Deadweight Loss? The Implications of Evasion and Avoidance." American Economic Journal: Economic Policy, 1(2): 31-52.

Clarke, George R. G., Lixin Colin Xu, and Heng-fu Zou. 2006. "Finance and Income Inequality: What Do the Data Tell Us?" Southern Economic Journal, 72(3): 578-596.

Clotfelter, Charles T. 1983. "Tax Evasion and Tax Rates: An Analysis of Individual Returns." The Review of Economics and Statistics, 65(3): 363-73.

Deaton, Angus. 1997. The Analysis of Household Surveys: A Microeconometric Approach to Development Policy. Baltimore, Maryland:Johns Hopkins University Press.

Dhami, Sanjit, and Ali Al-Nowaihi. 2007. "Why Do People Pay Taxes? Prospect Theory Versus Expected Utility Theory." Journal of Economic Behavior and Organization, 64(1): 171-192.

Easterly, William. 2007. "Inequality Does Cause Underdevelopment: Insights from a New Instrument." Journal of Development Economics, 84(2): 755-76.

Easterly, William, and Sergio Rebelo. 1993. "Marginal Income Tax Rates and Economic Growth in Developing Countries." European Economic Review, 37(2-3): 409-17. 
Egger, Peter, and Doina Maria Radulescu. 2009. "The Influence of Labour Taxes on the Migration of Skilled Workers." The World Economy, 32(9): 1365-1379.

Eissa, Nada, and Jeffrey B. Liebman. 1996. "Labor Supply Response to the Earned Income Tax Credit." Quarterly Journal of Economics, 111(2): 605-37.

Engstrom, Per, and Bertil Holmlund. 2009. "Tax Evasion and Self-employment in a High-tax Country: Evidence from Sweden." Applied Economics, 41(19): 2419-2430.

Feinstein, Jonathan S. 1991. "An Econometric Analysis of Income Tax Evasion and its Detection." The RAND Journal of Economics, 22(1): 14-35.

Feldstein, Martin. 1995. "The Effect of Marginal Tax Rates on Taxable Income: A Panel Study of the 1986 Tax Reform Act." Journal of Political Economy, 103(3): 551-72.

Fortin, Bernard, Guy Lacroix, and Marie-Claire Villeval. 2007. "Tax Evasion and Social Interactions." Journal of Public Economics, 91(11-12): 2089-2112.

Gordon, Roger, and Wei Li. 2007. "Puzzling Tax Structures in Devloping Countries: A Comparison of Two Alternative Explanations." Fiscal Policy and Management in East Asia, , ed. Takatoshi Ito and Andrew K. Rose Vol. 16, Chapter 1, 9-35. Chicago, Illinois:The Univerisity of Chicago Press.

Gordon, Roger, and Wei Li. 2009. "Tax structures in developing countries: Many puzzles and a possible explanation." Journal of Public Economics, 93(7-8): 855-866.

Gorodnichenko, Yuriy, Jorge Martinez-Vazquez, and Klara Sabirianova Peter. 2009. "Myth and Reality of Flat Tax Reform: Micro Estimates of Tax Evasion Response and Welfare Effects in Russia." Journal of Political Economy, 117(3): 504-554.

Gorodnichenko, Yuriy, Klara Sabirianova-Peter, and Dmitriy Stolyarov. 2009. "Inequality and Volatility Moderation in Russia: Evidence from Micro-Level Panel Data on Consumption and Income." Review of Economic Dynamics, 13(1): 209-237.

Gradstein, Mark, Branko Milanovic, and Yvonne Ying. 2001. "Democracy and Income In-Equality: An Empirical Analysis." The World Bank Policy Research Working Paper Series, No. 2561.

Gravelle, Jane G. 1992. "Equity Effects of the Tax Reform Act of 1986." Journal of Economic Perspectives, 6(1): 27-44.

Imbens, Guido W., and Joshua D. Angrist. 1994. "Identification and Estimation of Local Average Treatment Effects." Econometrica, 62(2): 467-475.

Kakwani, Nanok C. 1977. "Measurement of Tax Progressivity: An International Comparison." Economic Journal, 87(345): 71-80.

Kleibergen, Frank, and Richard Paap. 2006. "Generalized Reduced Rank Tests using the Singular Value Decomposition." Journal of Econometrics, 133(1): 97-126. 
Kleven, Henrik, Camille Landais, and Emmanuel Saez. 2010. "Taxation and International Migration of Superstars: Evidence from the European Football Market." National Bureau of Economic Research Working Paper, , (16545).

Kopczuk, Wojciech. 2005. "Tax Bases, Tax Rates and the Elasticity of Reported Income." Journal of Public Economics, 89(11-12): 2093-2119.

Law, Siong Hook, and Hui Boon Tan. 2009. "The Role of Financial Development on Income Inequality in Malaysia." Journal of Economic Development, 34(2): 153-168.

Lee, Young, and Roger H. Gordon. 2005. "Tax Structure and Economic Growth." Journal of Public Economics, 89(5-6): 1027-1043.

Lemieux, Thomas, Bernard Fortin, and Pierre Frechette. 1994. "The Effect of Taxes on Labor Supply in the Underground Economy." American Economic Review, 84(1): 23154 .

Martinez-Vazquez, Jorge. 2008. "The Impact of Budgets on the Poor: Tax and Expenditure Benefit Incidence Analysis." Public Finance for Poverty Reduction: Concepts and Case Studies from Africa and Latin America, , ed. Blanca Moreno-Dodson and Quentin Wodon, Chapter 5, 113-162. Washington DC:World Bank.

Meltzer, Allan H., and Scott F. Richard. 1981. "A Rational Theory of the Size of Government." Journal of Political Economy, 89(5): 914-27.

Milanovic, Branko. 1999. "Explaining the Increase in Inequality During Transition." Economics of Transition, 7(2): 299-341.

Milanovic, Branko. 2000. "The Median-Voter Hypothesis, Income Inequality, and Income Redistribution: An Empirical Test with the Required Data." European Journal of Political Economy, 16(3): 367-410.

Minarik, Joseph J. 1979. "The Size Distribution of Income During Inflation." Review of Income and Wealth, 25(4): 377-92.

Mirrlees, James A. 1971. "An Exploration in the Theory of Optimum Income Taxation." Review of Economic Studies, 38(114): 175-208.

Mookerjee, Rajen, and Paul Kalipioni. 2010. "Availability of Financial Services and Income Inequality: The Evidence from many Countries." Emerging Markets Review, 11(4): 404-408.

Musgrave, Richard, and Tun Thin. 1948. "Income Tax Progression, 1929-48." Journal of Political Economy, 56(6): 498-514.

OECD. 2011. "International Migration Outlook: SOPEMI 2011." OECD Publishing.

Perotti, Roberto. 1992. "Income Distribution, Politics, and Growth." American Economic Review, 82(2): 311-16. 
Persson, Torsten, and Guido Tabellini. 2002. "Political Economics and Public Finance." Handbook of Public Economics, , ed. Alan J. Auerbach and Martin Feldstein Vol. Volume 3, 1549-1659. Elsevier.

Ramsey, Frank. 1927. "A Contribution to the Theory of Taxation." Economic Journal, 37(145): 47-61.

Sabirianova Peter, Klara, Steve Buttrick, and Denvil Duncan. 2010. "Global Reform of Personal Income Taxation, 1981-2005: Evidence from 189 Countries." National Tax Journal, 63(3): 447-478.

Saez, Emmanuel, Joel Slemrod, and Seth H. Giertz. 2012. "The Elasticity of Taxable Income with Respect to Marginal Tax Rates: A Critical Review." Journal of Economic Literature, 50(1): 3-50.

Slemrod, Joel. 1985. "An Empirical Test for Tax Evasion." The Review of Economics and Statistics, 67(2): 232-38.

Slemrod, Joel. 1994. "On the High-Income Laffer Curve." Tax Progressivity and Income Inequality, , ed. Joel Slemrod, Chapter 6, 177-210. Cambridge University Press.

Slemrod, Joel, and Wojciech Kopczuk. 2002. "The optimal elasticity of taxable income." Journal of Public Economics, 84(1): 91-112.

Suits, Daniel B. 1977. "Measurement of Tax Progressivity." American Economic Review, 67(4): $747-52$.

Whalley, John. 1990. "Foreign Responses to U.S. Tax Reform." In Do taxes matter? The impact of the Tax Reform Act of 1986., ed. Joel Slemrod, Chapter 9, 286-314. MIT Press.

Yitzhaki, Shlomo. 1974. "IncomeTax Evasion: A Theoretical Analysis." Journal of Public Economics, 3(2): 201-202. 


\section{A Appendix A. Misclassification of Rich}

In appendix A, the model described in the paper is extended by introducing misclassification. That is, we allow the rich to act as poor by reporting income below the tax threshold. Consider an economy with three types of individuals; high non-compliant rich $(R H)$, low non-compliant rich $(R L)$, and poor $(\mathrm{P})$. Also assume individuals are identical to everyone within their respective group and that the only difference between $R H$ and $R L$ is the cost of evasion; $R H$ has a lower evasion cost than $R L .{ }^{36}$

All assumptions and definitions, except for the following, are as in the text. Define $\mu$ as the number of $R H$ as a share of the total observed poor and $\theta$ be the number of $R H$ as a share of total number of rich. Also assume $Y_{p}^{o}<Y_{p}^{*}<B, Y_{r h}^{o}<B<Y_{r h}^{*}$, and $B<Y_{r l}^{o}<Y_{r l}^{*}$, which allows us to write down observed and actual net income for the rich and poor as follows: ${ }^{37}$

Poor:

$$
\begin{aligned}
& y_{p}^{o}=Y_{p}^{o}\left(1-\tau_{p}\right) \\
& y_{p}^{*}=Y_{p}^{*}\left(1-\tau_{p}\right)+E_{p} \tau_{p}
\end{aligned}
$$

Rich:

$$
\begin{gathered}
y^{o}= \begin{cases}Y_{r h}^{o}\left(1-\tau_{p}\right) & \text { if "High Evader", } \\
Y_{r l}^{o}\left(1-\tau_{r}\right)+B\left(\tau_{r}-\tau_{p}\right) & \text { if "Low Evader" }\end{cases} \\
y^{*}= \begin{cases}Y_{r h}^{*}\left(1-\tau_{p}\right)+E_{r h} \tau_{p} & \text { if "High Evader", } \\
Y_{r l}^{*}\left(1-\tau_{r}\right)+B\left(\tau_{r}-\tau_{p}\right)+E_{r l} \tau_{r} & \text { if "Low Evader" }\end{cases}
\end{gathered}
$$

It can be shown that the average tax rate increases with reported income (See Panel $\mathrm{B}$ of Figure D). This implies that we can use the ratio of the average tax rates as a measure of progressivity and define an increase in progressivity as a decrease in $\tau_{p}$ or increase in $\tau_{r}$. To see the effect of progressivity on income inequality we define the Kuznets ratio as average income of the rich divided by the average income of the poor, and differentiate w.r.t. to $\tau_{r}$ and $\tau_{p}$, respectively.

\section{A.1 Observed Inequality}

Since the observed rich only includes $R L$ while the observed poor includes both $R H$ and $P$, we define the average income of the observed rich and poor as $y_{r l}^{o}$ and $\mu y_{r h}^{o}+(1-\mu) y_{p}^{o}$, respectively. This allows us to write down a measure of observed inequality:

$$
I^{o}=\frac{Y_{r l}^{o}\left(1-\tau_{r}\right)+B\left(\tau_{r}-\tau_{p}\right)}{\mu Y_{r h}^{o}\left(1-\tau_{p}\right)+(1-\mu) Y_{p}^{o}\left(1-\tau_{p}\right)}
$$

\footnotetext{
${ }^{36}$ This could be interpreted in any number of ways. One possibility is that the $R L$ rich have higher psychic cost than RH.

${ }^{37}$ The poor includes everyone whose actual income is less than the B. Note that the number of observed poor will be greater than the actual number of poor because some of the rich may choose to report income levels below B to reduce their tax legibility.
} 
Differentiating with respect to $\tau_{r}$ yields:

$$
\frac{\partial I^{o}}{\partial \tau_{r}}=\frac{A\left[Y_{r l}^{o^{\prime}}\left(1-\tau_{r}\right)-\left(Y_{r l}^{o}-B\right)\right]-y_{r l}^{o}\left[\left(1-\tau_{p}\right)\left[\mu Y_{r h}^{o^{\prime}}+Y_{r h}^{o} \mu^{\prime}\right]-Y_{p}^{o}\left(1-\tau_{p}\right) \mu^{\prime}\right]}{\left[\mu y_{r h}^{o}+(1-\mu) y_{p}^{o}\right]^{2}}
$$

which we rewrite as:

$$
\frac{\partial I^{o}}{\partial \tau_{r}}=\frac{\overbrace{A\left[Y_{r l}^{o^{\prime}}\left(1-\tau_{r}\right)-\left(Y_{r l}^{o}-B\right)\right]}-[\overbrace{y_{r l}^{o} \mu^{\prime}\left(y_{r h}^{o}-y_{p}^{o}\right)}+C[\mu \overbrace{\mu Y_{r h}^{o^{\prime}}}]]}{\left[\mu y_{r h}^{o}+(1-\mu) y_{p}^{o}\right]^{2}}
$$

where $A=\left[\mu y_{r h}^{o}+(1-\mu) y_{p}^{o}\right], C=y_{r l}^{o}\left(1-\tau_{p}\right)$, and $\mu^{\prime} \equiv \frac{\partial \mu}{\partial \tau_{r}} \geq 0$. The first term captures the indirect and direct effects on the "low evading" rich (RL). The net effect of these two components is to reduce observed inequality; i.e., an increase in $\tau_{r}$ leads to higher evasion, lower true income, and higher direct tax burden, which implies lower inequality. The second term captures the effect of switching status from low evader to high evader; that is, an increase in $\tau_{r}$ increases the payoff of being a high evader relative to being a low evader thus making it optimal for RL to switch status. In this framework, all the RL will switch to high evader status (since every RL is identical) thus reducing observed inequality. ${ }^{38}$ The last term reflects the response of $\mathrm{RH}$ to changes in $\tau_{r}$; the impact of this response is to increase observe inequality. However, it is likely that this effect will be zero if we assume RH do not respond to $\tau_{r}$. In other words, if $\mathrm{RH}$ respond to their marginal tax rate, $\tau_{p}$, then a change in $\tau_{r}$ should have no intensive margin effects, implying this term would be zero. If, then, we make this assumption, an increase in progressivity via an increase in $\tau_{r}$ reduces observed inequality.

Next, we consider the effect of a change in progressivity via a change in $\tau_{p}$. That is, we differentiate equation $(21)$ with respect to $\tau_{p}$ :

$$
\begin{gathered}
\frac{\partial I^{o}}{\partial \tau_{p}}=\frac{-A B-y_{r l}^{o}\left[\mu^{\prime} y_{r h}^{o}-\mu Y_{r h}^{o}+\mu\left(1-\tau_{p}\right)\left(Y_{r h}^{o^{\prime}}\right)-\mu^{\prime} y_{p}^{o}-\Omega Y_{p}^{o}+\Omega\left(1-\tau_{p}\right)\left(Y_{p}^{o^{\prime}}\right)\right]}{\left[\mu y_{r h}^{o}+\Omega y_{p}^{o}\right]^{2}} \\
\frac{\partial I^{o}}{\partial \tau_{p}}=\frac{-A B-y_{r l}^{o}\left[\mu^{\prime}\left(y_{r h}^{o}-y_{p}^{o}\right)-\left(\mu Y_{r h}^{o}+\eta Y_{p}^{o}\right)+\left(1-\tau_{p}\right)\left[\mu Y_{r h}^{o^{\prime}}+\eta Y_{p}^{o^{\prime}}\right]\right]}{\left[\mu y_{r h}^{o}+\eta y_{p}^{o}\right]^{2}} \\
\frac{\partial I^{o}}{\partial \tau_{p}}=\frac{y_{r l}^{o}\left(\mu Y_{r h}^{o}+\eta Y_{p}^{o}\right)-A B-y_{r l}^{o}\left[\mu^{\prime}\left(y_{r h}^{o}-y_{p}^{o}\right)+\left(1-\tau_{p}\right)\left[\mu Y_{r h}^{o^{\prime}}+\eta Y_{p}^{o^{\prime}}\right]\right]}{\left[\mu y_{r h}^{o}+\eta y_{p}^{o}\right]^{2}}
\end{gathered}
$$

\footnotetext{
${ }^{38}$ One can easily imagine a more general framework where the psychic cost of hiding a given level of income is distributed between 0 and 1 . Only some of the RL would find it optimal to switch in this case. However, the effect on the distribution of income would be the same as above.
} 
If we rewrite $\mathrm{A}$ as $\left(\mu Y_{r h}^{o}+\eta Y_{p}^{o}\right)\left(1-\tau_{p}\right)$ then:

$$
\frac{\partial I^{o}}{\partial \tau_{p}}=\frac{D \overbrace{\left[y_{r l}^{o}-\left(1-\tau_{p}\right) B\right]}-y_{r l}^{o}[\overbrace{\left(1-\tau_{p}\right)\left[\mu Y_{r h}^{o^{\prime}}+\eta Y_{p}^{o^{\prime}}\right.}]+\overbrace{\mu^{\prime}\left(y_{r h}^{o}-y_{p}^{o}\right)}]}{\left[\mu y_{r h}^{o}+\eta y_{p}^{o}\right]^{2}}
$$

where $\eta=(1-\mu), D=\left[\mu y_{r h}^{o}+(1-\mu) y_{p}^{o}\right]$, and $\mu^{\prime} \equiv \frac{\partial \mu}{\partial \tau_{p}} \geq 0$. Again, we find an ambiguous effect. The first two terms imply a negative relationship between progressivity and observed inequality. ${ }^{39}$ However, because an increase in $\tau_{p}$ reduces net income of $R L$ more than it reduces net income of $R H, R L$ will switch status, thus moderating the effect of the first two components. ${ }^{40}$

\section{A.2 Actual Inequality}

Next we consider the effect of progressivity on actual inequality. We define actual inequality as the average actual income of the rich divided by the average actual income of the poor. Assuming a fraction $\theta$ of the rich are "high evaders" and $(1-\theta)$ are "low evaders" we write the inequality measure as:

$$
I^{*}=\frac{\theta\left[Y_{r h}^{*}\left(1-\tau_{p}\right)+E_{r h} \tau_{p}\right]+(1-\theta)\left[Y_{r l}^{*}\left(1-\tau_{r}\right)+B\left(\tau_{r}-\tau_{p}\right)+E_{r l} \tau_{r}\right]}{\left[Y_{p}^{*}\left(1-\tau_{p}\right)+E_{p} \tau_{p}\right]}
$$

Differentiating with respect to $\tau_{r}$ yields:

$$
\frac{\partial I^{*}}{\partial \tau_{r}}=\frac{y_{p}^{*}\left[\theta^{\prime} y_{r h}^{*}+\theta y_{r h}^{*^{\prime}}-\theta^{\prime} y_{r l}^{*}+(1-\theta)\left(Y_{r l}^{*^{\prime}}\left(1-\tau_{r}\right)-Y_{r l}^{*}+B+E_{r l}^{\prime} \tau_{r}+E_{r l}\right)\right]}{\left[y_{p}^{*}\right]^{2}}
$$

add and subtract $\theta E_{r h}^{\prime} \&(1-\theta) E_{r l}^{\prime}$ then rewrite as:

$$
\begin{aligned}
& \frac{\partial I^{*}}{\partial \tau_{r}}= \\
& \frac{y_{p}^{*}\left[\theta^{\prime}\left(y_{r h}^{*}-y_{r l}^{*}\right)+\theta\left[\left(1-\tau_{p}\right) Y_{r h}^{o^{\prime}}+E_{r h}^{\prime}\right]+(1-\theta)\left[\left(1-\tau_{r}\right) Y_{r l}^{o^{\prime}}+E_{r l}^{\prime}-\left(Y_{r l}^{o}-B\right)\right]\right]}{\left[y_{p}^{*}\right]^{2}}
\end{aligned}
$$

and with respect to $\tau_{p}$ yields:

$$
\frac{\partial I^{*}}{\partial \tau_{p}}=\frac{y_{p}^{*}\left[\theta^{\prime} y_{r h}^{*}+\theta y_{r h}^{*^{\prime}}-\theta^{\prime} y_{r l}^{*}-(1-\theta) B\right]-F y_{p}^{*}}{\left[y_{p}^{*}\right]^{2}}
$$

\footnotetext{
${ }^{39}$ Note that an increase in $\tau_{p}$ implies a decrease in progressivity. Therefore, a positive relationship between $\tau_{p}$ and inequality is consistent with a negative relationship between progressivity and inequality.

${ }^{40}$ We assume $\left(y_{r h}^{o} \geq y_{p}^{o}\right)$; i.e., the "high evaders" are still ranked above the poor.
} 
add and subtract $E_{r h}^{\prime} \& E_{p}^{\prime}$ then rewrite as:

$$
\frac{\partial I^{*}}{\partial \tau_{p}}=\frac{y_{p}^{*}\left[\theta^{\prime}\left(y_{r h}^{*}-y_{r l}^{*}\right)+\theta\left[\left(1-\tau_{p}\right) Y_{r h}^{o^{\prime}}+E_{r h}^{\prime}-Y_{r h}^{o}\right]-(1-\theta) B\right]-F y_{p}^{*}}{\left[y_{p}^{*}\right]^{2}}
$$

where $F=\theta y_{r h}^{*}+(1-\theta) y_{r l}^{*}, \frac{\partial \theta}{\partial \tau_{r}} \geq 0$ and $\frac{\partial \theta}{\partial \tau_{p}} \geq 0$. The sign of the relationship is ambiguous in both cases regardless of the assumptions we make.

\section{A.3 Government Transfers}

In this section we extend the model by allowing for government transfers. We assume some exogenous share, $\delta$, of total tax revenues is shared equally among the observed poor. The remaining $(1-\delta)$ is used to cover tax administration costs and/or public goods. We define total tax revenues (TR) and total government transfer $\mathrm{G}$ as:

$$
\begin{aligned}
T R & =\left(Y_{p}^{o}+Y_{r h}^{o}\right) \tau_{p}+Y_{r l}^{o} \tau_{r}-B\left(\tau_{r}-\tau_{p}\right) \\
G & =\delta\left[\left(Y_{p}^{o}+Y_{r h}^{o}\right) \tau_{p}+Y_{r l}^{o} \tau_{r}-B\left(\tau_{r}-\tau_{p}\right)\right]
\end{aligned}
$$

Let $N=R H+P$ be the total number of observed poor and write the average income of the observed poor as $\mu\left(Y_{r h}^{o}\left(1-\tau_{p}\right)\right)+(1-\mu)\left(Y_{p}^{o}\left(1-\tau_{p}\right)\right)+\frac{G}{N}$. Observed income inequality may be written as:

$$
I^{o}=\frac{Y_{r l}^{o}\left(1-\tau_{r}\right)+B\left(\tau_{r}-\tau_{p}\right)}{\mu\left(Y_{r h}^{o}\left(1-\tau_{p}\right)\right)+(1-\mu)\left(Y_{p}^{o}\left(1-\tau_{p}\right)\right)+\frac{G}{N}}
$$

Differentiating with respect to $\tau_{r}$ yields:

$$
\frac{\partial I^{o}}{\partial \tau_{r}}=\frac{\overbrace{A\left[Y_{r l}^{o^{\prime}}\left(1-\tau_{r}\right)-\left(Y_{r l}^{o}-B\right)\right]}-[\overbrace{y_{r l}^{o} \mu^{\prime}\left(y_{r h}^{o}-y_{p}^{o}\right)}+C[\overbrace{\mu Y_{r h}^{o^{\prime}}}]]+G^{\prime}}{\left[\mu y_{r h}^{o}+(1-\mu) y_{p}^{o}\right]^{2}}
$$

where $A=\left[\mu y_{r h}^{o}+(1-\mu) y_{p}^{o}\right], C=y_{r l}^{o}\left(1-\tau_{p}\right), G^{\prime}=\frac{\delta}{N}\left[\tau_{p} Y_{r h}^{o^{\prime}}+\tau_{r} Y_{r l}^{o^{\prime}}+\left(Y_{r l}^{o}-B\right)\right]$ and $\frac{\partial \mu}{\partial \tau_{r}} \geq 0$. Note that $G^{\prime}$ will be positive if the economy is on the upward sloping side of the Laffer curve. That is, an increase in $\tau_{r}$ increases tax revenues and thus transfers to the observed poor. While the sign of equation (28) remains unclear (just as equation (22)), it is clear that the sign of equation (28) is more likely to be negative than equation (22). In other words, the introduction of pro-poor government transfers increases the redistributive power of the personal income tax. ${ }^{41}$

The effect of $\tau_{p}$ on observed inequality can be obtained similarly:

\footnotetext{
${ }^{41}$ Of course, these conclusions do not hold if higher taxes reduce tax revenues. In this case, higher taxes lead to a reduction in tax revenues thus reducing transfers.
} 


$$
\frac{\partial I^{o}}{\partial \tau_{p}}=\frac{A \overbrace{\left[Y_{r l}^{o}-\left(1-\tau_{p}\right) B\right]}-y_{r l}^{o}[\overbrace{\left(1-\tau_{p}\right)\left[\mu Y_{r h}^{o^{\prime}}+(1-\mu) Y_{p}^{o^{\prime}}\right.}]+\overbrace{\mu^{\prime}\left(y_{r h}^{o}-y_{p}^{o}\right)}+G^{\prime}]}{\left[\mu y_{r h}^{o}+(1-\mu) y_{p}^{o}\right]^{2}}
$$

where $A=\left(\mu y_{r h}^{o}+(1-\mu) y_{p}^{o}\right), \frac{\partial \mu}{\partial \tau_{p}} \geq 0$, and $G^{\prime}=\frac{\delta}{N}\left[\left(Y_{p}^{o}+Y_{r h}^{o}\right)+\left(Y_{p}^{o^{\prime}}+Y_{r h}^{o^{\prime}}\right) \tau_{p}+B\right]$. In this case we see that introducing transfers makes it more likely that $\frac{\partial I^{o}}{\partial \tau_{p}} \leq 0 .{ }^{42}$ That is, the higher transfers will cause reported income among the observed poor to be higher than it otherwise would be.

Finally, we determine the effect of a change in $\tau_{r}$ and $\tau_{p}$ on actual inequality. Recall some of the rich will receive government transfers due to their reporting status. Therefore, we can write the average actual income of the rich as:

$$
\begin{aligned}
\bar{y}_{r}^{*} & =\frac{\sum_{i}^{r h}\left(y_{r h}^{*}+\frac{G}{r h+p}\right)+\sum_{j}^{r l} y_{r l}^{*}}{r h+r l} \\
& =\frac{r h y_{r h}^{*}+\frac{r h G}{r h+p}+r l y_{r l}^{*}}{r h+r l} \\
& =\theta y_{r h}^{*}+(1-\theta) y_{r l}^{*}+\frac{\theta G}{r h+p}
\end{aligned}
$$

thus,

$$
I^{*}=\frac{\theta\left(Y_{r h}^{*}\left(1-\tau_{p}\right)+E_{r h} \tau_{p}\right)+(1-\theta)\left[Y_{r l}^{*}\left(1-\tau_{r}\right)+B\left(\tau_{r}-\tau_{p}\right)+E_{r l} \tau_{r}\right]+\frac{\theta G}{r h+p}}{\left(Y_{p}^{*}\left(1-\tau_{p}\right)+E_{p} \tau_{p}\right)+\frac{G}{r h+p}}
$$

Differentiating with respect to $\tau_{r}$ yields equation (25) with the following term added to the numerator:

$$
\frac{1}{r h+p} \overbrace{G^{\prime}\left[\theta\left(y_{p}^{*}+G_{p}\right)-\left(\theta y_{r h}^{*}+(1-\theta) y_{r l}^{*}\right)\right.}]+\overbrace{\theta^{\prime} G\left(y_{p}^{*}+G_{p}\right)}
$$

The sign of the first term is negative if we impose the assumption that the economy is on the upward sloping side of the Laffer curve, while the second term is positive. Therefore, adding this term to equation (25) does not change the ambiguity of the sign of (25).

Similarly, differentiating with respect to $\tau_{p}$ yields equation (26) with the following term added to the numerator:

$$
\frac{G^{\prime}}{r h+p} \overbrace{\left[\theta\left(y_{p}^{*}+G_{p}\right)-\left(\theta y_{r h}^{*}+(1-\theta) y_{r l}^{*}\right)\right.}]+\overbrace{\theta^{\prime} \frac{G}{r h+p}\left(y_{p}^{*}+G_{p}\right)}
$$

Again, we see that the sign is ambiguous.

In the above exercises, we assumed every observed poor received a transfer from the government. Relaxing this assumption does not change the results in any significant way. In particular, the sign remains ambiguous even if we assume the transfers are properly targeted.

\footnotetext{
${ }^{42}$ This assumes we are on the upward sloping portion of the Laffer curve
} 


\section{B Appendix B. Pro-poor Redistribution}

This appendix explores the distributional impact of structural progressivity in the presence of government transfers. It continues from equation (11) by explicitly specifying the partial effects in equation (12). Recall that observed income inequality is written as:

$$
I^{o}=\frac{Y_{r}^{o}\left(1-\tau_{r}\right)+B\left(\tau_{r}-\tau_{p}\right)}{Y_{p}^{o}\left(1-\tau_{p}\right)+\frac{G}{n_{p}}} .
$$

Differentiating with respect to $\tau_{p}$ yields:

$$
\begin{aligned}
& \frac{\partial I^{o}}{\partial \tau_{p}}=\frac{y_{p}^{o}(-B)}{\left[y_{p}^{o}\right]^{2}}-\frac{y_{r}^{o}\left[\left(1-\tau_{p}\right)\left(Y_{p}^{*^{\prime}}-E_{p}^{\prime}\right)-Y_{p}^{o}\right]}{\left[y_{p}^{o}\right]^{2}}-\frac{y_{r}^{o} G^{\prime}}{n_{p}\left[y_{p}^{o}\right]^{2}} \\
& \frac{\partial I^{o}}{\partial \tau_{p}}=\frac{y_{r}^{o} Y_{p}^{o}-B\left(Y_{p}^{o}\left(1-\tau_{p}\right)+\frac{G}{n_{p}}\right)}{\left[y_{p}^{o}\right]^{2}}-\frac{y_{r}^{o}\left(1-\tau_{p}\right)\left(Y_{p}^{*^{\prime}}-E_{p}^{\prime}\right)}{\left[y_{p}^{o}\right]^{2}}-\frac{y_{r}^{o} G^{\prime}}{n_{p}\left[y_{p}^{o}\right]^{2}}, \\
& \frac{\partial I^{o}}{\partial \tau_{p}}=\frac{\overbrace{\left(1-\tau_{r}\right)\left(Y_{r}^{o}-B\right) Y_{p}^{o}}-\overbrace{\left(1-\tau_{p}\right) y_{r}^{o} Y_{p}^{*^{\prime}}}+\overbrace{\left(1-\tau_{p}\right) y_{r}^{o} E_{p}^{\prime}}}{\left[y_{p}^{o}\right]^{2}}-\overbrace{\frac{\left(B G+y_{r}^{o} G^{\prime}\right)}{n_{p}\left[y_{p}^{o}\right]^{2}}} \gtrless 0,
\end{aligned}
$$

where $G^{\prime}=\frac{\partial G}{\partial \tau_{p}}=\delta\left[n_{p}\left(Y_{p}^{o}+Y_{p}^{o^{\prime}} \tau_{p}\right)+n_{r} B\right]$. The key difference between equations (34) and (5) is the term involving $G$ and $G^{\prime}$. Also note that the sum of the first three terms is positive, which implies a negative relationship between progressitiviy (induced by a change in $\tau_{p}$ ) and inequality in observed income; just as in equation (5). Because $G^{\prime}$ is assumed to be positive, the sign of equation (34) is ambiguous. However, we can conclude that the effect of progressivity on observed inequality is smaller in equation (34) than in equation (5). ${ }^{43}$

Next, we determine the effect of a change in $\tau_{r}$ and $\tau_{p}$ on actual inequality. We write actual income inequality as:

$$
I^{*}=\frac{Y_{r}^{*}\left(1-\tau_{r}\right)+B\left(\tau_{r}-\tau_{p}\right)+E_{r} \tau_{r}}{Y_{p}^{*}\left(1-\tau_{p}\right)+E_{p} \tau_{p}+\frac{G}{n_{p}}}
$$

and differentiate with respect to $\tau_{r}$ and then $\tau_{p}$.

$$
\frac{\partial I^{*}}{\partial \tau_{r}}=\frac{y_{p}^{*}\left[Y_{r}^{*^{\prime}}-\tau_{r} Y_{r}^{*^{\prime}}-Y_{r}^{*}+\tau_{r} E_{r}^{\prime}+E_{r}+B\right]-y_{r}^{*}\left[\frac{G^{\prime}}{n_{p}}\right]}{\left[y_{p}^{*}\right]^{2}}
$$

Similar to equation (7), we can rewrite this expression as

\footnotetext{
${ }^{43}$ This assumes we are on the upward sloping portion of the Laffer curve.
} 


$$
\left.\frac{\partial I^{*}}{\partial \tau_{r}}=\frac{-\overbrace{\left(Y_{r}^{o}-B\right)}+\overbrace{\left(1-\tau_{r}\right) Y_{r}^{*^{\prime}}}+\overbrace{\tau_{r} E_{r}^{\prime}}}{y_{p}^{*}}-\frac{y_{r}^{*} G^{\prime}}{n_{p}\left[y_{p}^{*}\right]^{2}}\right] \gtrless 0,
$$

where $y_{p}^{*}$ now includes government transfers. Similarly, differentiating with respect to $\tau_{p}$ yields:

$$
\frac{\partial I^{*}}{\partial \tau_{p}}=\frac{\left.y_{p}^{*}(-B)-y_{r}^{*}\left[\left(1-\tau_{p}\right) Y_{p}^{*^{\prime}}-Y_{p}^{*}+\tau_{p} E_{p}^{\prime}+E_{p}\right)\right]}{\left[y_{p}^{*}\right]^{2}}-\frac{y_{r}^{*} G^{\prime}}{n_{p}\left[y_{p}^{*}\right]^{2}},
$$

which we can rewrite as:

$$
\begin{array}{r}
\frac{\partial I^{*}}{\partial \tau_{p}}=\frac{\overbrace{\left(1-\tau_{r}\right)\left(Y_{r}^{o}-B\right) Y_{p}^{o}+Y_{p}^{o} Y_{r}^{o}\left(\pi_{r}-\pi_{p} \sigma\right)}^{\left[y_{p}^{*}\right]^{2}}-\overbrace{\left(1-\tau_{p}\right) y_{r}^{*} Y_{p}^{*^{\prime}}}-\overbrace{\tau_{p} y_{r}^{*} E_{p}^{\prime}}}{-\overbrace{\frac{B G+y_{r}^{*} G^{\prime}}{n_{p}\left[y_{p}^{*}\right]^{2}}} \gtrless 0,}
\end{array}
$$

Although it is not clear whether the sign in equation (36) is positive or negative, we can conclude that the effect in equation (36) is larger than that in equation (7) and smaller than the effect in equation (11). Similarly, we may conclude that increased progressivity via a change in $\tau_{p}$ is more likely to reduce income inequality in equation (37) than in equation (8). I

These results indicate that, pro-poor government transfers increase the redistributive effect of $\tau_{r}$ and $\tau_{p}$ on both observed and actual net income.

\section{Appendix C. Data from the Review of Economic Dynamics}

Consumption based measures of the GINI coefficient is often not available for developed countries. Additionally, country level GINI estimates, where available, are generally subjected to issues of consistency due to differences in variable definitions. The Review of Economic Dynamics (RED) published a recent series on inequality, which includes consistent measures of income and consumption based GINI coefficients for 9 countries. ${ }^{44}$ These GINI measures of inequality are used to supplement the UN-WIIDER data. This section describes the process used to extract and clean the RED data.

The RED sample includes GINI coefficients for several measures of income and consumption/expenditure. We extract all GINI coefficients on household disposable income, household income (when it is clear that this refers to gross income), and consumption. The

\footnotetext{
${ }^{44}$ See footnote 15 for the list of coutnries.
} 
selected income measures are after transfers where available and all measures are representative of a national sample and have been adjusted for household size. Because of the breath of information provided for these estimates, they are all given the highest quality rating in the WIIDER data set. Finally, we merge the RED sample with the WIIDER sample and use the RED data to replace missing values in the WIIDER sample. We also replace non-missing WIIDER data points with corresponding RED data. Therefore, our final data set includes all estimates taken from the RED sample. 


\section{Appendix D. Tables and Figures}

Table 7: Sample Composition

\begin{tabular}{llcc}
\hline \multirow{2}{*}{ Auxiliary Variable } & Categories & \multicolumn{2}{c}{ Sample } \\
\cline { 3 - 4 } Income Base & Consumption & 27.32 & 28.17 \\
& Gross income & 30.33 & 32.53 \\
& Net income & 42.35 & 39.30 \\
\hline \multirow{3}{*}{ Income Adjustment } & ES used & 40.93 & 34.90 \\
& Per capita/head & 35.26 & 39.87 \\
& No adjustment & 17.01 & 17.61 \\
& Unknown & 6.80 & 7.62 \\
\hline \multirow{3}{*}{ Area coverage } & National & 95.12 & 94.70 \\
& Urban & 3.17 & 3.36 \\
& Other & 1.70 & 1.94 \\
\hline \multirow{3}{*}{ Quality } & 1 & 47.79 & 42.05 \\
& 2 & 31.12 & 33.95 \\
& 3 & 21.09 & 24.01 \\
\hline \multirow{3}{*}{ Data Source } & RED & 21.20 & 18.13 \\
& Eurostat & 1.98 & 1.66 \\
& ILO & 3.17 & 2.84 \\
& WDI & 5.05 & 5.54 \\
& WIDER & 68.59 & 71.83 \\
\hline
\end{tabular}

Each category of auxiliary variable is a dummy variable. Some GINI estimates have national coverage, but with exclusions. These estimates are grouped with the Urban estimates. The quality categories are defined as follows: 1) underlying concepts known and judged sufficient; 2) income concept or survey is problematic or unknown or estimates not verified; 3) income concept and survey are problematic or unknown. RED=Review of Income and Dynamics, ILO=International Labor Organization, WDI=World Development Indicators, and WIDER=World Institute for Development Economics Research. 
Table 8: Description of Variables

\begin{tabular}{|c|c|}
\hline Variable & Definition \\
\hline GINI coefficient & $\begin{array}{l}\text { The measure of income inequality used is the GINI Coefficient reported by } \\
\text { RED, EUROSTAT, ILO, WDI, and WIIDER. The data are based on house- } \\
\text { hold surveys conducted in the respective countries except for Sweden, which } \\
\text { also uses administrative data based on actual tax returns. }\end{array}$ \\
\hline High income & $\begin{array}{l}\text { High Income is a dummy variable that classifies countries by per capita gross } \\
\text { national income in US } \$ \text {. High income }=1 \text { if high or upper middle income } \\
\text { country and } 0 \text { if lower middle or low income countries. } \\
\text { Source: World Development Indicators }\end{array}$ \\
\hline \multicolumn{2}{|r|}{ Tax variables } \\
\hline & $\begin{array}{l}\text { The source for all tax variables is World Tax Indicators v.1 (Sabirianova Peter, } \\
\text { Buttrick and Duncan, 2010). }\end{array}$ \\
\hline Top rate $(\%)$ & $\begin{array}{l}\text { Top statutory PIT rate. Legally determined marginal tax rate applicable to } \\
\text { the top bracket of the personal income tax schedule. }\end{array}$ \\
\hline MRP & $\begin{array}{l}\text { MRP characterizes the structural progressivity of national tax schedules with } \\
\text { respect to the changes in marginal rates along the income distribution. It is } \\
\text { the slope coefficient from regressing actual marginal tax rates on the log of } \\
\text { gross income for the income distribution up to } 4 \text { y income. }\end{array}$ \\
\hline ARP & $\begin{array}{l}\text { ARP characterizes the structural progressivity of national tax schedules with } \\
\text { respect to the changes in average rates along the income distribution. It is } \\
\text { the slope coefficient from regressing actual average tax rates on the log of } \\
\text { gross income for the income scale up to } 4 y \text { income, where y is a country's per } \\
\text { capita GDP. }\end{array}$ \\
\hline ARP-bottom & Average rate progression for the income scale up to $2 \mathrm{y}$ income. \\
\hline ARP-middle & Average rate progression for the income scale between $1^{*} \mathrm{y}$ and $3 y$ income. \\
\hline ARP-top & Average rate progression for the income scale between $2^{*} \mathrm{y}$ and $4 \mathrm{y}$ income. \\
\hline \multicolumn{2}{|r|}{ Instrumental variables } \\
\hline Progressivity & $\begin{array}{l}\text { The mean of neighbors' tax progressivity measures (defined above). Three } \\
\text { definitions of neighbors is used: contiguous neighbors, neighbors of a country's } \\
\text { contiguous neighbors, and five closest neighbors. The latter is used for Island } \\
\text { economies only and refers to distance between capital cities. Each neighbor } \\
\text { is weighted equally when calculating mean progressivity measures. }\end{array}$ \\
\hline Complexity & $\begin{array}{l}\text { Complexity is a time-varying index that summarizes several observable di- } \\
\text { mensions of the PIT schedule, including the complexity of allowances and tax } \\
\text { credits, the use of multiple tax schedules, non-standard tax formulas, local } \\
\text { taxes, national surtaxes, and the number of PIT brackets. It is measured on a } \\
10 \text { point scale from } 0 \text { - } 9 \text {, where } 0 \text { is lowest complexity. Neighbors are defined } \\
\text { above. Each neighbor is weighted equally when calculating mean complexity } \\
\text { measures. }\end{array}$ \\
\hline \multicolumn{2}{|r|}{ Institutional variables } \\
\hline Law and order & $\begin{array}{l}\text { The law and order index is an assessment of the strength and impartiality of } \\
\text { the legal system as well as an assessment of popular observance of the law. } \\
\text { The index is on the scale from } 0 \text { to } 6 \text {, with } 0 \text { representing the worst law and } \\
\text { order. The law and order index is available for the period 1984-2005. } \\
\text { Source: International Country Risk Guide (ICRG). }\end{array}$ \\
\hline Corruption & $\begin{array}{l}\text { The corruption index is an assessment of corruption within the political sys- } \\
\text { tem. The index is on the scale from } 0 \text { to } 6 \text {, with } 0 \text { representing the worst case } \\
\text { of corruption. The corruption index is available for the period 1984-2005. } \\
\text { Source: International Country Risk Guide (ICRG). }\end{array}$ \\
\hline Civil liberties & $\begin{array}{l}\text { The civil liberties index gives an indication of the extent to which individuals } \\
\text { are allowed freedoms of expression and belief, associational and organiza- } \\
\text { tional rights, rule of law, and personal autonomy without interference from } \\
\text { the state. The original index is reversed on the scale from } 1-7 \text {, with } 1 \text { repre- } \\
\text { senting no freedom. } \\
\text { Source: Freedom House }\end{array}$ \\
\hline
\end{tabular}

continues on next page 
Political rights The political rights index gives an indication of the extent to which individuals are allowed to participate freely in the political process, including the right to vote freely for distinct alternatives in legitimate elections, compete for public office, join political parties and organizations, and elect representatives who have a decisive impact on public policies and are accountable to the electorate. The original index is reversed on the scale from 1-7, with 1 representing no freedom.

Source: Freedom House

\begin{tabular}{|c|c|}
\hline \multicolumn{2}{|r|}{ Financial Development } \\
\hline Asset share & $\begin{array}{l}\text { Deposit money bank assets / (Deposit money + Central) bank assets. ".... } \\
\text { [A]ssets include claims on the whole nonfinancial real sector, including gov- } \\
\text { ernment, public enterprises and the private sector." }\end{array}$ \\
\hline Deposits & $\begin{array}{l}\text { Financial system deposits / GDP. Financial system deposits includes "... all } \\
\text { checking, savings and time deposits in banks and bank-like financial institu- } \\
\text { tions ..." }\end{array}$ \\
\hline & Source: Beck, Demirg-Kunt and Levine (2000) \\
\hline Interest rate spread $(\%)$ & $\begin{array}{l}\text { "Interest rate spread is the interest rate charged by banks on loans to prime } \\
\text { customers minus the interest rate paid by commercial or similar banks for } \\
\text { demand, time, or savings deposits." }\end{array}$ \\
\hline & Source: World Development Indicators \\
\hline \multicolumn{2}{|r|}{ Other control variables } \\
\hline
\end{tabular}

Per capita GDP Per capita Gross Domestic Product is calculated using GDP (in US\$ at 1990 prices) divided by country population. We use the logged value in time $t-1$ in the empirical analysis.

Inflation rate (\%) $\quad$ Sources: United Nations Common Database (UNCD). Sources: IMF IFS (2006), IMF WEO (2006), ILO Laborsta (2006), EIU (2005), and IMF WEO annual reports

Exchange rate (\%) Currency annual depreciation rate with respect to USD, end of period Sources: IMF IFS (2006)

Population

Total population Source: United Nations

Religion Dominant religion. We define a religion as dominant if (1) it is the only religion OR (2) the share of population practicing the religion is greater than twice the share of the second largest group and the share of largest group is greater than $40 \%$ Source: Authors calculations based on data from the CIA factbook

Auxiliary variables

\begin{tabular}{ll}
\hline & Auxiliary variables \\
\hline & The auxiliary variables define various characteristics of the GINI coefficient: \\
& Income Base, Income Adjustment, National, and Quality. \\
This refers to the income base used to estimate the GINI coefficient. Our \\
estimation sample includes three income bases: Consumption, gross income, \\
and net income. \\
This variable is used to identify GINI estimates that have been adjusted \\
for household size and the type of adjustment. The four primary types of \\
adjustment are household size, square root of household size, OECD scale, \\
and modified OECD scale; the first is coded as "Per capita/head" and the \\
others as "ES used" in our data. We also identify GINI estimates that ignore \\
household size "No adjustment" and those for which there is no indication \\
that an adjustment has been made "Unknown". \\
This is a dummy variable based on area coverage, which refers to the geo- \\
graphic area covered by the surveys that form the basis of the GINI data. \\
Area coverage includes national, all urban, all rural, selected urban, selected \\
rural, and unknown coverage. National is equal to 1 if area coverage is na- \\
tional and zero otherwise. \\
This variable classifies the quality of the GINI estimates on a three point \\
scale defined as follows: 1 indicates underlying concepts known and judged \\
sufficient; 2 indicates income concept or survey is problematic or unknown \\
or estimates not verified; and 3 indicates income concept and survey are \\
problematic or unknown.
\end{tabular}


Table 9: Effect of Progressivity on Observed Income Inequality

\begin{tabular}{|c|c|c|c|c|}
\hline & \multicolumn{2}{|c|}{ OLS } & \multicolumn{2}{|c|}{ IV } \\
\hline & MRP & ARP & MRP & ARP \\
\hline \multirow[t]{2}{*}{ Progressivity } & -0.068 & $-0.559 * *$ & $-3.151^{* *}$ & $-3.180 * * *$ \\
\hline & $(0.194)$ & $(0.243)$ & $(1.292)$ & $(1.040)$ \\
\hline \multirow[t]{2}{*}{ LL(per capita GDP) } & $15.317^{* *}$ & $13.908^{* *}$ & $16.551^{* *}$ & 5.498 \\
\hline & $(6.309)$ & $(6.377)$ & $(8.301)$ & $(7.931)$ \\
\hline \multirow[t]{2}{*}{ LL(per capita GDP)sq } & $-1.046^{* * *}$ & $-0.924^{* *}$ & $-0.880^{*}$ & -0.201 \\
\hline & $(0.376)$ & $(0.385)$ & $(0.533)$ & $(0.527)$ \\
\hline \multirow[t]{2}{*}{ Ln(Population) } & 0.093 & 0.021 & $1.202^{*}$ & -0.095 \\
\hline & $(0.411)$ & $(0.413)$ & $(0.706)$ & $(0.503)$ \\
\hline \multirow[t]{2}{*}{ Inflation } & -0.000 & 0.000 & -0.001 & 0.004 \\
\hline & $(0.003)$ & $(0.003)$ & $(0.003)$ & $(0.002)$ \\
\hline \multirow[t]{2}{*}{ Asset share } & $-14.015^{* * *}$ & $-14.526^{* * *}$ & $-18.913^{* *}$ & $-18.121^{* * *}$ \\
\hline & $(5.376)$ & $(5.366)$ & $(7.673)$ & $(6.329)$ \\
\hline \multirow[t]{2}{*}{ Asset share dummy } & $10.435^{*}$ & $11.166^{*}$ & $13.750^{*}$ & $15.218^{* *}$ \\
\hline & $(5.810)$ & $(5.794)$ & $(8.081)$ & $(6.706)$ \\
\hline \multirow[t]{2}{*}{ Muslim } & 2.536 & 3.627 & $12.593^{* *}$ & $10.095^{* *}$ \\
\hline & $(3.318)$ & $(3.277)$ & $(5.392)$ & $(4.056)$ \\
\hline \multirow[t]{2}{*}{ Catholic } & $8.894^{* * *}$ & $8.948^{* * *}$ & $14.359^{* * *}$ & $9.840^{* * *}$ \\
\hline & $(3.292)$ & $(3.221)$ & $(3.794)$ & $(2.986)$ \\
\hline \multirow[t]{2}{*}{ Protestant } & $8.518^{* *}$ & $8.883^{* * *}$ & $14.671^{* *}$ & $8.683^{* *}$ \\
\hline & $(3.337)$ & $(3.280)$ & $(5.727)$ & $(4.159)$ \\
\hline \multirow[t]{2}{*}{ Mixed } & 3.633 & 4.445 & $11.442^{* *}$ & $8.724^{* *}$ \\
\hline & $(3.354)$ & $(3.341)$ & $(5.612)$ & $(4.170)$ \\
\hline \multirow[t]{2}{*}{ Christian - mixed } & 4.915 & $5.761^{*}$ & $16.655^{* * *}$ & $11.256^{* * *}$ \\
\hline & $(3.341)$ & $(3.141)$ & $(5.480)$ & $(3.307)$ \\
\hline \multirow[t]{2}{*}{ Buddism/Hinduism } & $8.532^{* * *}$ & $8.524^{* * *}$ & $13.259^{* * *}$ & $6.877^{*}$ \\
\hline & $(3.282)$ & $(3.212)$ & $(4.928)$ & $(3.961)$ \\
\hline \multirow[t]{2}{*}{ Quality $=2$} & 2.224 & 1.998 & 1.936 & 0.490 \\
\hline & $(1.758)$ & $(1.684)$ & $(2.456)$ & $(1.837)$ \\
\hline \multirow[t]{2}{*}{ Quality $=3$} & $4.641^{* *}$ & $3.932^{* *}$ & 2.356 & -0.044 \\
\hline & $(1.937)$ & $(1.927)$ & $(2.739)$ & $(2.267)$ \\
\hline \multirow[t]{2}{*}{ Per Capita Adjustment } & 2.958 & 2.615 & 1.306 & 0.477 \\
\hline & $(1.813)$ & $(1.775)$ & $(2.147)$ & $(1.972)$ \\
\hline \multirow[t]{2}{*}{ No Adjustment } & $-3.355^{*}$ & $-3.707^{* *}$ & $-5.778 * *$ & $-5.448 * *$ \\
\hline & $(1.813)$ & $(1.810)$ & $(2.785)$ & $(2.509)$ \\
\hline \multirow[t]{2}{*}{ Unknown Adjustment } & -3.992 & -4.088 & -6.150 & -4.921 \\
\hline & $(3.173)$ & $(3.115)$ & $(4.669)$ & $(3.740)$ \\
\hline
\end{tabular}


continued from previous page

\begin{tabular}{lcccc}
\hline National Coverage & 2.434 & 3.095 & $7.029^{* *}$ & $6.469^{* *}$ \\
& $(2.460)$ & $(2.370)$ & $(3.278)$ & $(2.736)$ \\
\hline $1985-1990$ & 2.023 & 1.638 & -1.801 & -0.757 \\
& $(1.476)$ & $(1.400)$ & $(2.452)$ & $(1.739)$ \\
$1991-1995$ & 2.778 & 2.354 & -0.919 & -0.601 \\
& $(1.767)$ & $(1.750)$ & $(2.945)$ & $(2.409)$ \\
$1995-2000$ & $3.223^{*}$ & 2.838 & -0.409 & 0.195 \\
& $(1.791)$ & $(1.768)$ & $(2.938)$ & $(2.413)$ \\
$2001-2005$ & 1.609 & 0.880 & -4.706 & -3.398 \\
& $(1.929)$ & $(1.877)$ & $(3.545)$ & $(2.741)$ \\
\hline Gross Income & $7.878^{* * *}$ & $7.639^{* * *}$ & $8.648^{* * *}$ & $6.402^{* * *}$ \\
Constant & $(1.270)$ & $(1.299)$ & $(2.176)$ & $(1.691)$ \\
& -30.689 & -24.380 & -58.514 & 8.305 \\
Under ID - Pvalue & $(30.345)$ & $(30.568)$ & $(38.381)$ & $(35.169)$ \\
F-Stat & 15.206 & 15.636 & 0.007 & 0.001 \\
N & 1282 & 1282 & 5.809 & 9.582 \\
\end{tabular}

Robust standard errors adjusted for clustering at the country level are in parentheses; * significant at $10 \%$; ** significant at $5 \%$; *** significant at 1\%. All models are estimated with sampling weights (see Section 4.1 for details on weighting procedure). The dependent variable is GINI in gross or net income. The GINI is measured on a scale from 0 to 100 and has a mean of 36 with standard deviation of 10 in the estimation sample. LL(per capita GDP) is the lagged value of logged per capita GDP. Asset share is the ratio of deposit money bank assets to all bank assets. Missing observations for asset share are coded as zero and "asset share dummy" ( $=1$ if asset share $=0)$ is included in the model. Only 9 percent of the estimation sample is affected by this procedure. The omitted categories for dummy variables are no religion, quality $=1$ (best quality), equivalent scale adjustment, 1981-1985, and net income. 

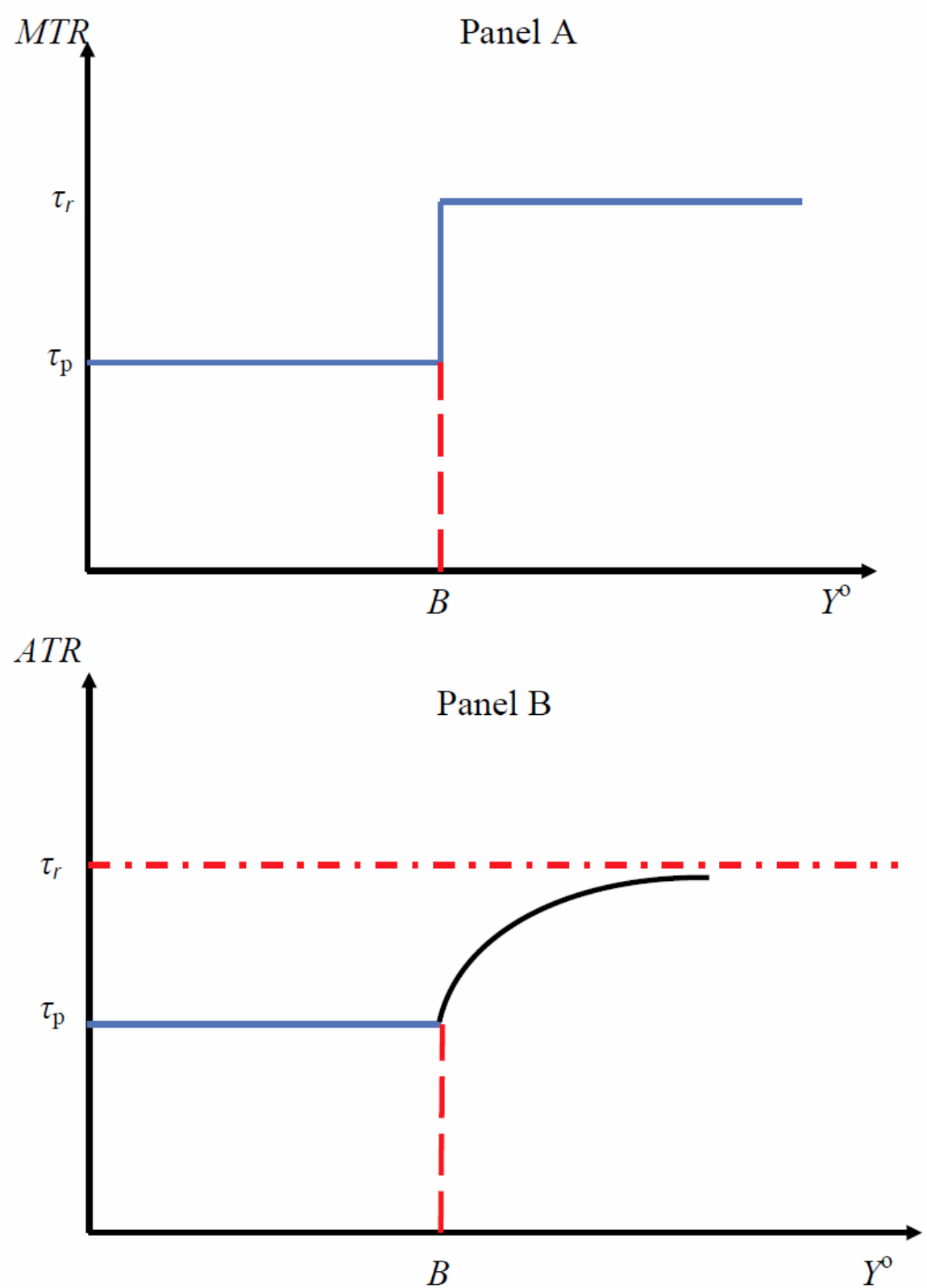

Figure 4: Marginal and Average Tax Rate

Panel A illustrates the two rate personal income tax schedule used in the section 2.1. $\tau_{r}$ and $\tau_{p}$ are the statutory marginal tax rates for the upper and lower brackets, respectively. $B$ is the tax threshold, $Y^{o}$ is observed gross income, and $M T R$ is the marginal tax rate.

Panel B illustrates how average tax rate varies with reported income. $\tau_{r}$ and $\tau_{p}$ are the statutory marginal tax rates for the upper and lower brackets, respectively. $B$ is the tax threshold and $Y^{\circ}$ is observed gross income. The average tax rate, $A T R$, is defined as tax liability divided by observed gross income. This is equal to $\tau_{p}$ if $Y^{o}<B$ and $\tau_{r}-\left(\tau_{r}-\tau_{p}\right) * B / Y^{o}$ if $Y^{o}>B$. 


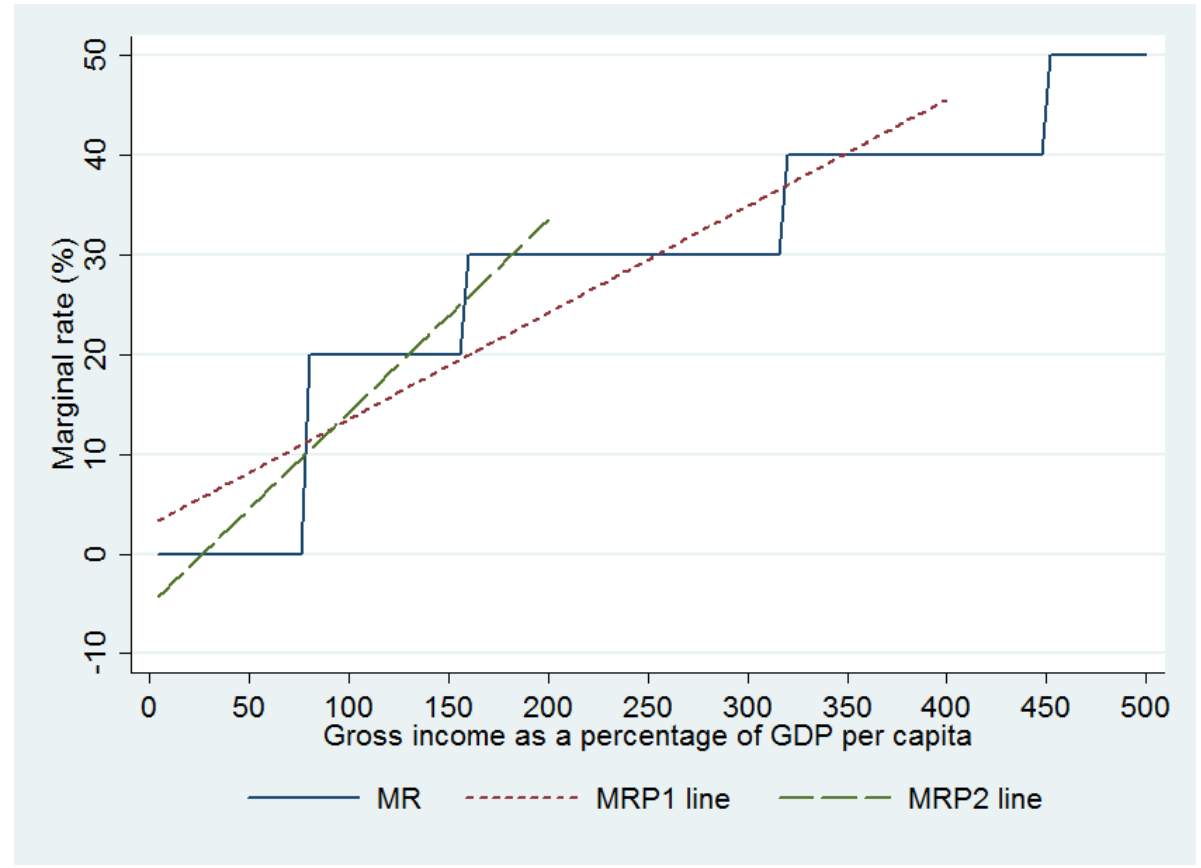

Figure 5: Average Rate Progression: Illustrative Example

This figure depicts a hypothetical schedule of marginal rates (MR), with top statutory PIT rate $50 \%$ and no deductions and tax credits. Average rate progression (ARP) is the estimated slope coefficient from regressing average rates on gross income (as percent of per capita GDP). ARP is calculated for gross income from $4 \%$ to $400 \%$ of $y$, ARP-bottom is calculated for gross income from $4 \%$ to $200 \%$ of $y$, where $y$ is a country's per capita GDP. 